Istituto d'Igiene dell'Università di Roma (Direttore: Prof. V. Del Vecchio)

Centro di Studi della Microcitemia di Roma (Direttore: Prof. E. Silvestroni) e Sezione di Ferrara (Direttore: Prof. M. Ortolani)

\title{
Presenza di Emoglobina «L» nel Ferrarese e di Emoglobina «D» nel Bolognese
}

\author{
Silvestroni E., Bianco I., Lucci R., Soffritti E.
}

Nel corso degli ultimi due anni sono stati individuati nel Ferrarese ed illustrati in alcune note preliminari da due di noi ( $\mathrm{I}-2-3), 5$ ceppi familiari di soggetti portatori di $\mathrm{Hb}$ lenta. Recentemente la massima parte di questi soggetti è stata riesaminata sia dal lato ematologico per uno studio approfondito dei rapporti fra $\mathrm{Hb}$ lenta $\mathrm{e}$ microcitemia, sia dal lato biochimico per un'esatta caratterizzazione e classificazione dei vari tipi di $\mathrm{Hb}$ abnorme.

I rapporti fra $\mathrm{Hb}$ lenta e microcitemia saranno illustrati e discussi in altro lavoro; nella presente nota vengono illustrate le caratteristiche biochimiche, elettroforetiche e cromatografiche delle emoglobine lente di questi 5 ceppi familiari.

\section{Materiale e metodi}

La prima famiglia (schema I della fig. I), di origine ferrarese, comprende 4 soggetti portatori di Hb lenta: i due fratelli G. Ercole e G. Servilio, e le due figlie gemelle di G. Ercole, Franca e Francesca.

La seconda famiglia (schema II della fig. I), di origine ferrarese, comprende due sorelle, S. Amalia e S. Teresa, portatrici di Hb lenta e microcitemia, e complessivamente altri ro loro discendenti, anch'essi portatori di Hb lenta. Un figlio di S. Amalia (B. Duilio) risulta inoltre coniugato con donna microcitemica ed ha una figlia affetta da grave anemia eritroblastica e portatrice di Hb lenta (B. Antonella).

Nel terzo ceppo familiare (schema III della fig. I), anch'esso ferrarese, dal capostipite (B. Primo) portatore di Hb lenta, discendono tre figli e tre nipoti anch'essi portatori di $\mathrm{Hb}$ lenta.

La quarta famiglia (schema IV della fig. I), anch'essa di origine ferrarese come le precedenti, comprende due sorelle, Z. Gina e Geolinda, portatrici di Hb lenta e microcitemia e sei loro discendenti, di cui tre (C. Eufemia, O. Vincenzo e M. Livia) portatori di $\mathrm{Hb}$ lenta e tre portatori di microcitemia.

Nella quinta famiglia (schema $\mathrm{V}$ della fig. I), di origine bolognese, figurano tre soggetti portatori di $\mathrm{Hb}$ lenta: il capostipite A. Roberto, sua figlia A. Franca e il figlio di questa, B. Massimo. 

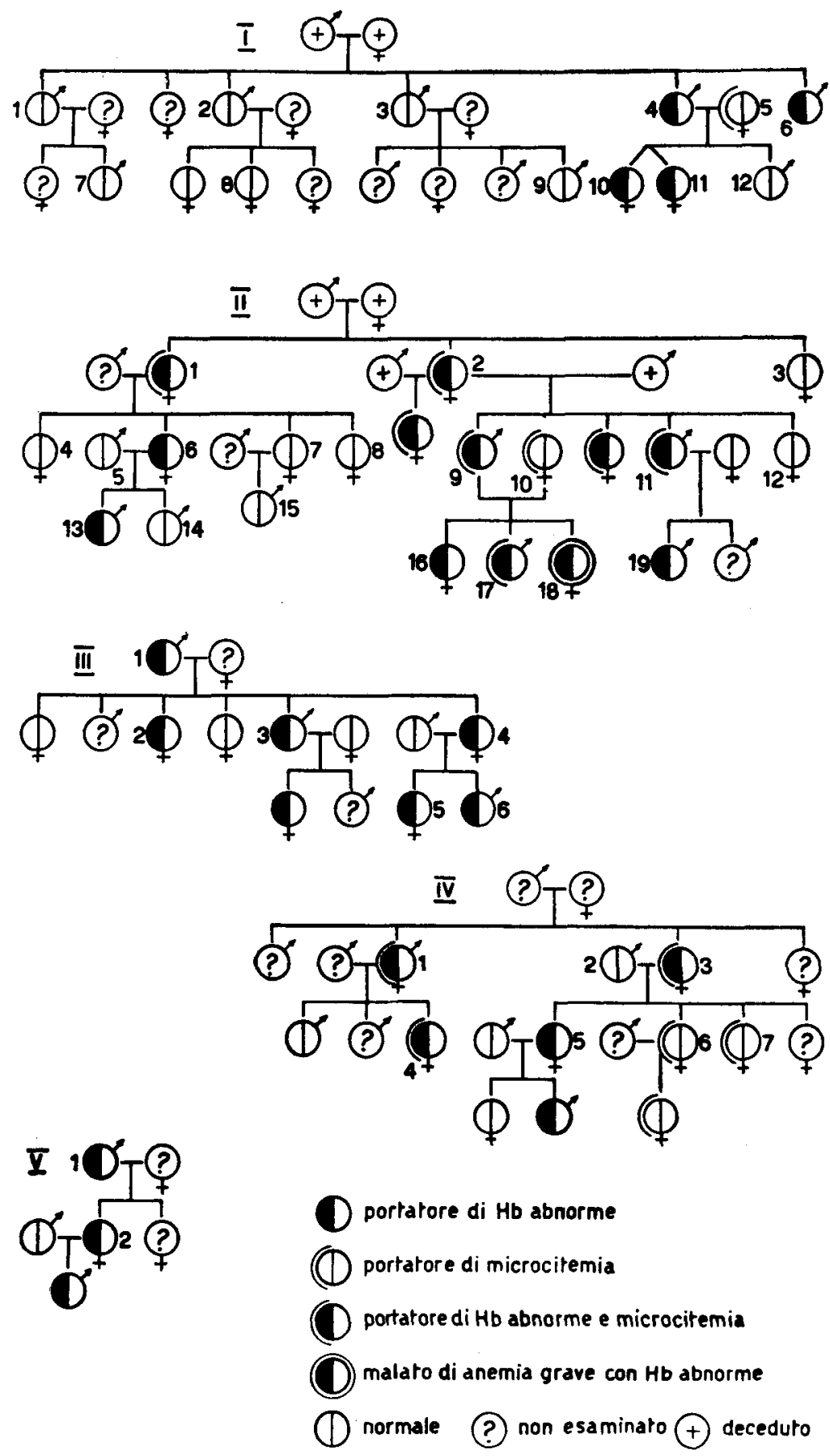

Fig. I. Alberi genealogici delle 5 famiglie di portatori di Hb abnorme. Il numero a fianco dei simboli corrisponde al numero riportato nella Tabella I a fianco di ciascun soggetto 
Ad eccezione della bimba B. Antonella di anni I, affetta da grave anemia clinicamente assai simile al morbo di Cooley, tutti gli altri portatori di $\mathrm{Hb}$ lenta non presentano segni clinici di emopatia e sono in complesso soggetti sani.

Per lo studio dell'Hb lenta sono state eseguite le seguenti indagini:

1. elettroforesi su carta secondo le akituali tecniche in uso presso il Centro di Studi della Microcitemia di Roma (4), con tampone di glicina a pH 8,6, forza ionica 0,04, e colorazione con blu di bromofenolo;

2. elettroforesi su carta a $\mathrm{pH}$ acido con la stessa apparecchiatura dell'elettroforesi alcalina ma con l'impiego di tampone di fosfato a $\mathrm{pH} 6,5$, forza ionica 0,04 , e successiva colorazione con blu di bromofenolo;

3. elettroforesi su blocco d'amido con tampone di glicina a $\mathrm{pH} 8,6$ e forza ionica o, I2, secondo la tecnica adottata nel Centro di Studi della Microcitemia di Roma (5);

4. elettroforesi a pH alcalino secondo Smithies (6) in tampone di borato a forza ionica 0,012 , e a $\mathrm{pH}$ acido secondo Fessas e Mastrokalos (7) in tampone di fosfato a forza ionica 0,03 , su amido solubile Merk che ha dimostrato in esperimenti preparatori eseguiti nel Centro di Studi della Microcitemia di Roma un potere risolutivo delle varie frazioni emoglobiniche maggiore di quello del comune amido di patata; e che permette sia l'eluizione delle varie frazioni, sia lo studio di esse dopo colorazione con amido-schwarz;

5. elettroforesi in gel d'amido a pH acido secondo Fessas e Mastrokalos (7), con amido idrolizzato Connaught, tampone di fosfato a $\mathrm{pH} \mathrm{6,5}$, forza ionica 0,03 , e colorazione con amido schwarz;

6. elettroforesi su gel d'agar secondo Robinson e Coll. (8), in tampone di citrato a $\mathrm{pH} \mathrm{6,4}$, forza ionica 0,05 ; e successiva colorazione con blu di bromofenolo;

7. cromatografia su Amberlite IRC 50 secondo Huisman e Prins (9), a pH 6, con tampone di citrato a forza ionica 0,05 ;

8. dosaggio allo spettrofotometro Beckmann DU, a $540 \mathrm{~m} \mu$, delle varie frazioni emoglobiniche eluite dopo elettroforesi su blocco d'amido;

9. dosaggio dell'Hb alcali-resistente $(\mathrm{Hb} a-r)$ secondo la tecnica di Singer e Coll. (Io);

Io. studio della solubilità dell'Hb secondo la tecnica di Itano (I I);

Ir. determinazione allo spettrofotometro Beckmann DU, secondo le tecniche adottate nel Centro di Studi della Microcitemia di Roma (5), delle curve di assorbimento fra 2.800 e $3.000 \AA$ della frazione emoglobinica lenta e dell'Hb $A_{1}$, e determinazione per le stesse frazioni del rapporto fra le densità ottiche a 2.800 e 4 . I $50 \AA$;

I2. studio secondo la tecnica di Liquori e Bertinotti (12), modificata (5), del comportamento di fronte agli alcali della frazione lenta e della frazione $\mathrm{A}_{1}$ isolate dopo elettroforesi su blocco d'amido, e determinazione per entrambe del rapporto $\frac{\mathrm{E}_{\mathrm{d}}}{\mathrm{E}_{\mathrm{o}} / 2}$, dove $\mathrm{E}_{\mathrm{d}}=\mathrm{E}_{5.800} \AA$ della soluzione al termine della denaturazione $\mathrm{e} \mathrm{E}_{\mathrm{o}}=\mathrm{E}_{5.800} \AA$ della soluzione prima dell'aggiunta di $\mathrm{NaOH}$. 


\section{Risultati}

Famiglia $I$ - All'elettroforesi su carta a pH alcalino la frazione emoglobinica lenta, presente in 4 membri della famiglia, mostra, com'è stato già segnalato in un precedente lavoro (I), mobilità praticamente identica a quella dell'Hb S (fig. 2). Non sembra significativa una differenza minima di velocità, osservata solo saltuariamente, nel senso di una mobilità maggiore della frazione lenta in confronto a quella della

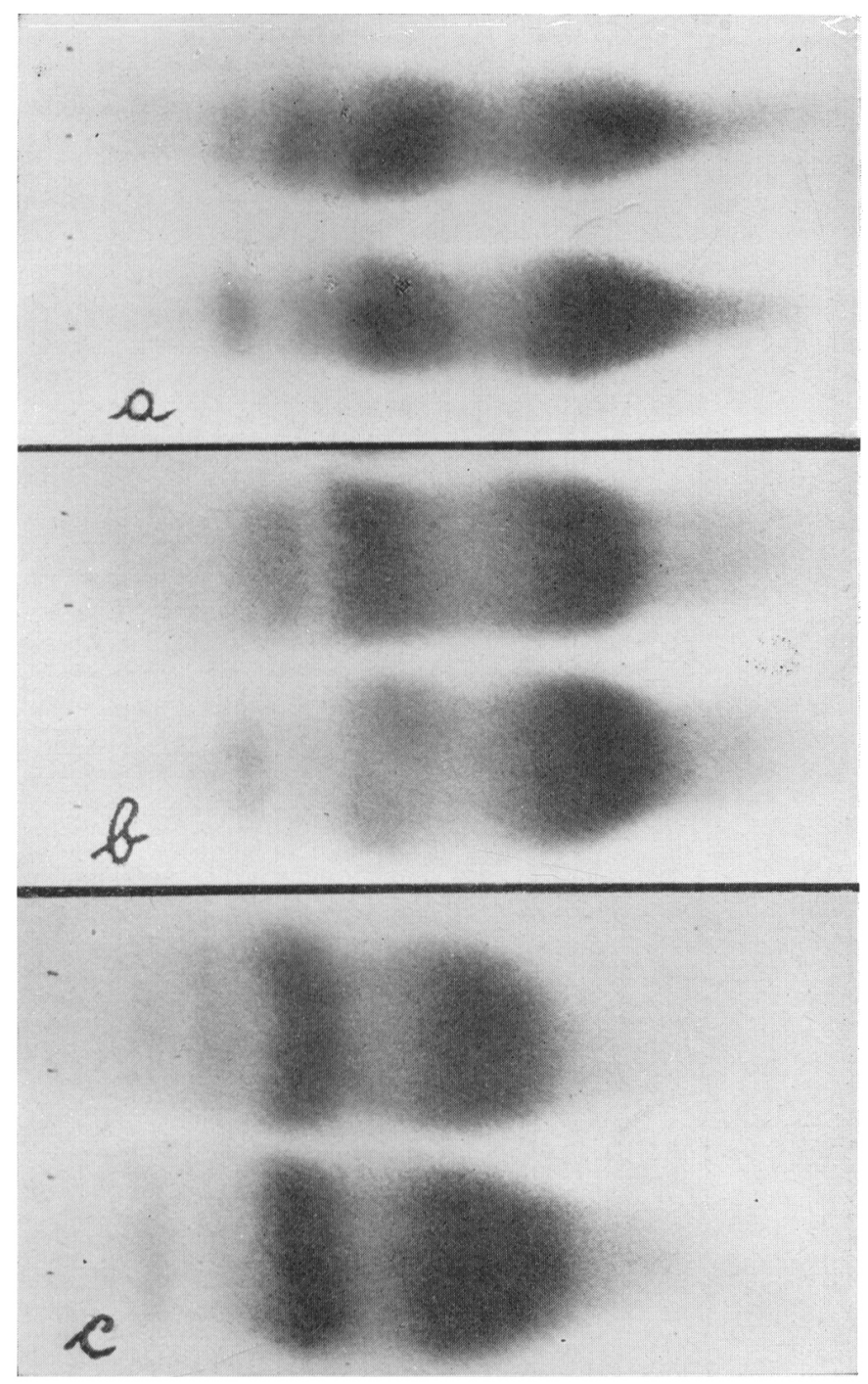

Fig. 2. Elettroforesi su carta a $\mathrm{pH}$ alcalino. Confronto di mobilità elettroforetica fra $\mathrm{Hb} \mathrm{A}-\mathrm{S}$ ed $\mathrm{Hb}$ lenta della famiglia I. Dall'alto al basso: in $a \mathrm{Hb} \mathrm{A-S} \mathrm{e} \mathrm{Hb}$ di G. Servilio; in $b \mathrm{Hb} \mathrm{A-S} \mathrm{e} \mathrm{Hb}$ di $\mathrm{G}$. Ercole; in $c$ $\mathrm{Hb}$ A-S e Hb di G. Franca. Uguaglianza di mobilità elettroforetica della frazione $\mathrm{S}$ e della frazione lenta della famiglia $\mathrm{I}$ 


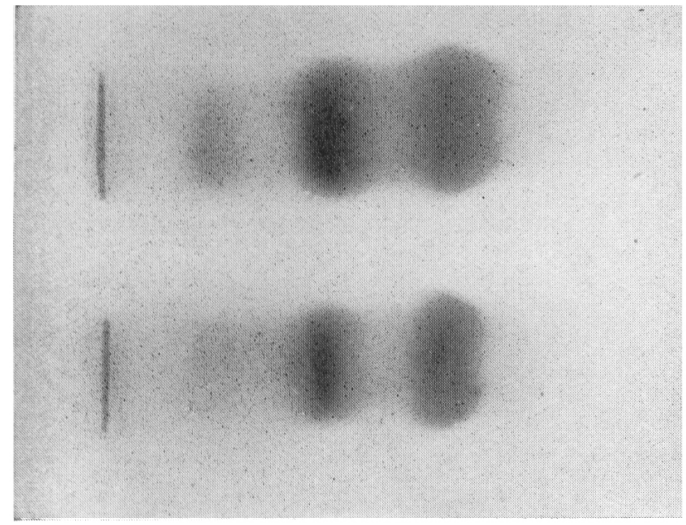

Fig. 3. Elettroforesi a pH alcalino su amido solubile Merk. In alto $\mathrm{Hb} \mathrm{A}-\mathrm{S}$, in basso $\mathrm{Hb}$ di G. Servilio. Assoluta eguaglianza di comportamento delle due emoglobine

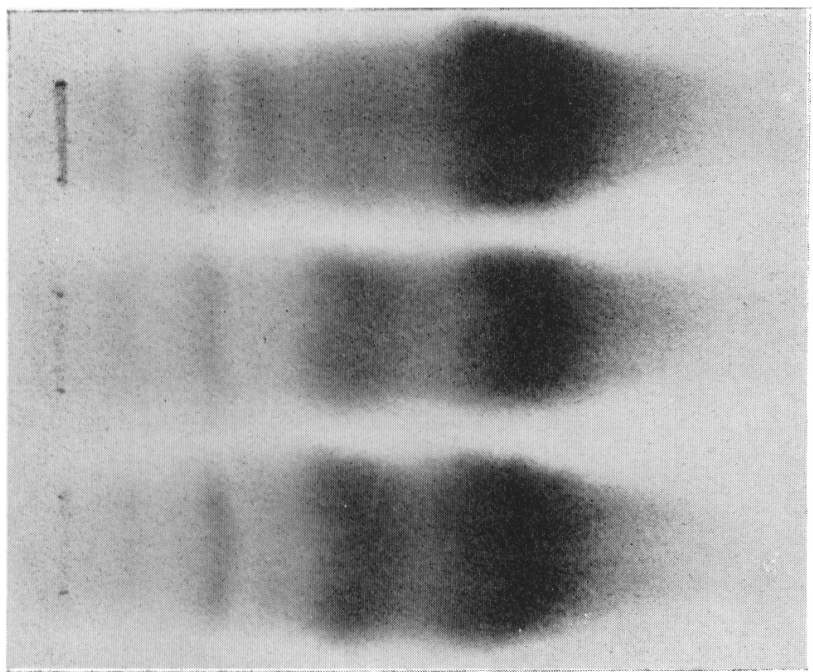

Fig. 6. Elettroforesi su gel d'amido a $\mathrm{pH}$ acido di varie emoglobine lente. Dall'alto al basso: $\mathrm{Hb}$ di P. Nadia, $\mathrm{Hb}$ di B. Au* gusto, Hb di G. Ercole. Aspetto normale di tutte le emoglobine, senza frazionamenti della macchia principale

Fig. 7. Elettroforesi su gel d'agar a $\mathrm{pH}$ acido di $\mathrm{Hb}$ A-S (in alto) e di $\mathrm{Hb}$ di G. Ercole (in basso). Separazione in ambedue le emoglobine di una identica frazione lenta
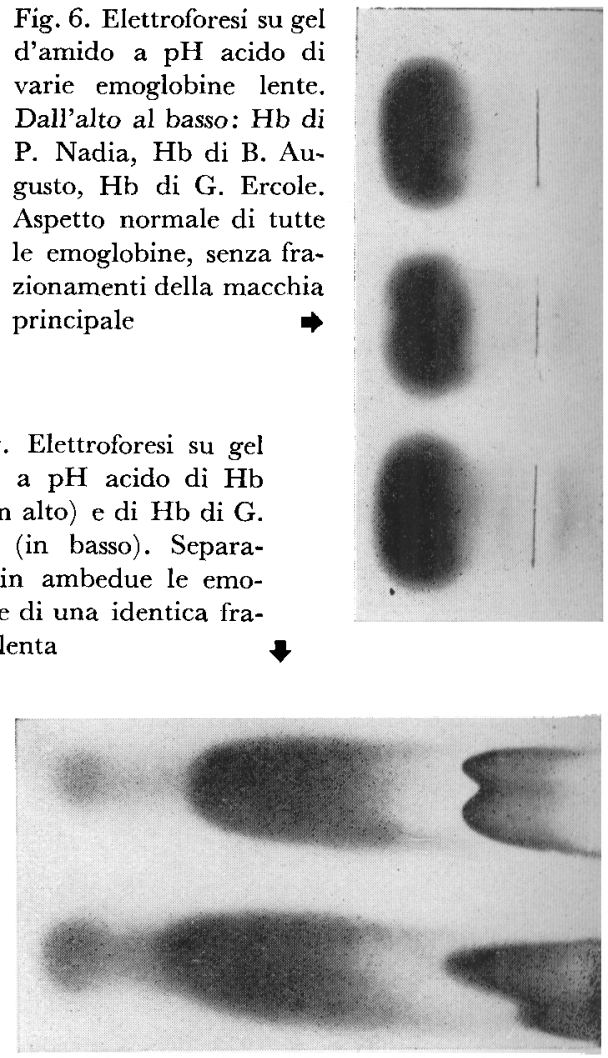

Fi. 5. Elettroforesi su piastra d'amido a $\mathrm{pH}$ acido di emoglobine diverse. Dall'alto al basso: $\mathrm{Hb}$ di S. Teresa, $\mathrm{Hb}$ di G. Servilio, $\mathrm{Hb}$ di B. Antonio, $\mathrm{Hb} \mathrm{A}-\mathrm{S}, \mathrm{Hb}$ microcitemica (F. Oriele). Aspetto eguale di tutte le emoglobine, e assenza di frazionamento in seno alla macchia principale di $\mathrm{Hb}$

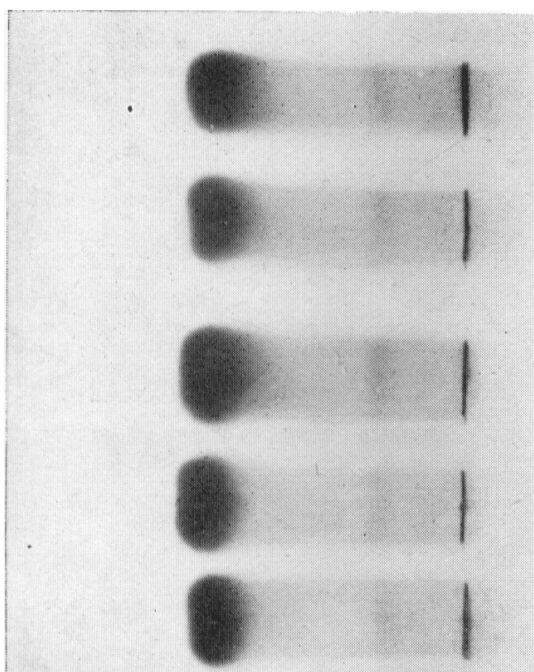

\section{定}

Fig. 8. Cromatografia su Amberlite IRC 50 a $\mathrm{pH}$ acido di $\mathrm{Hb}$ di G. Franca $(a)$ e di G. Servilio (c) a confronto con $\mathrm{Hb}$ A-S $(b)$. Presenza nelle prime due emoglobine di una frazione molto più lenta della frazione $\mathrm{S}(\mathrm{Hb} \mathrm{L})$ e suddivisa in due bande ravvicinate. Ben visibile la frazione $A_{2}$, lievemente più rapida della frazione $\mathrm{S}$

Fig. 4. Elettroforesi su carta a pH alcalino di emoglobine lente delle famiglie I e II. Dall'alto al basso: B. Gabriele, G. Francesca, G. Franca. Notare in B. Gabriele la frazione $\mathrm{A}_{2}$ abbondante e la frazione lenta scarsa e dotata di mobilità lievemente maggiore di quella dell'Hb lenta degli altri due soggetti 


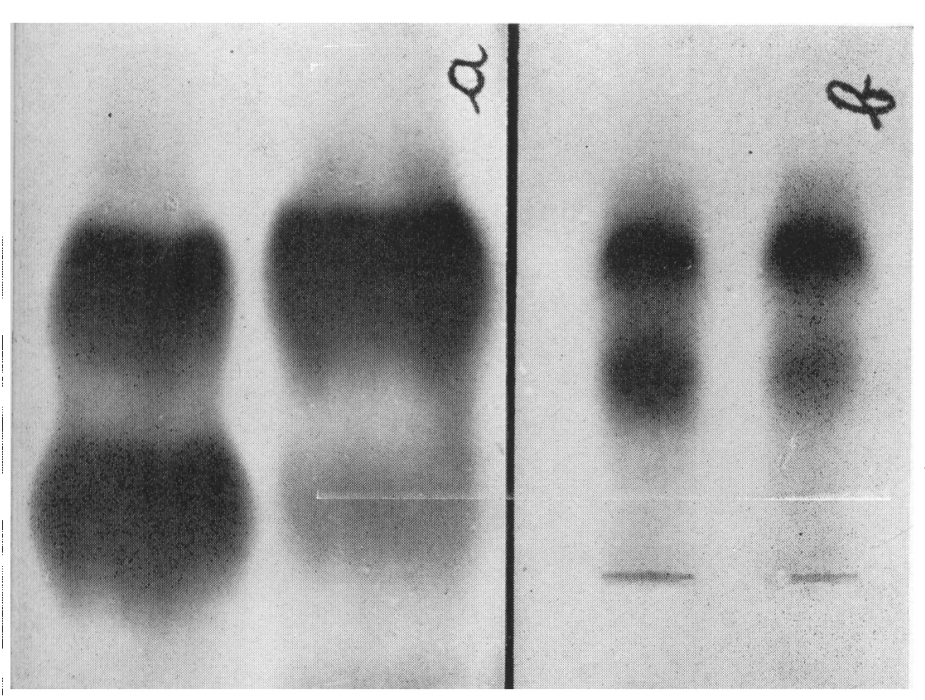

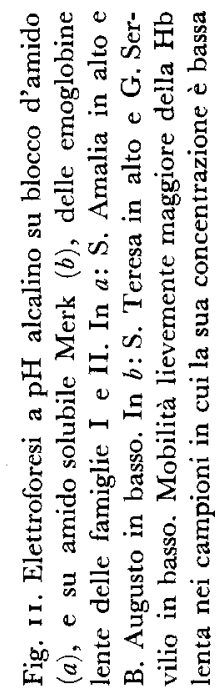
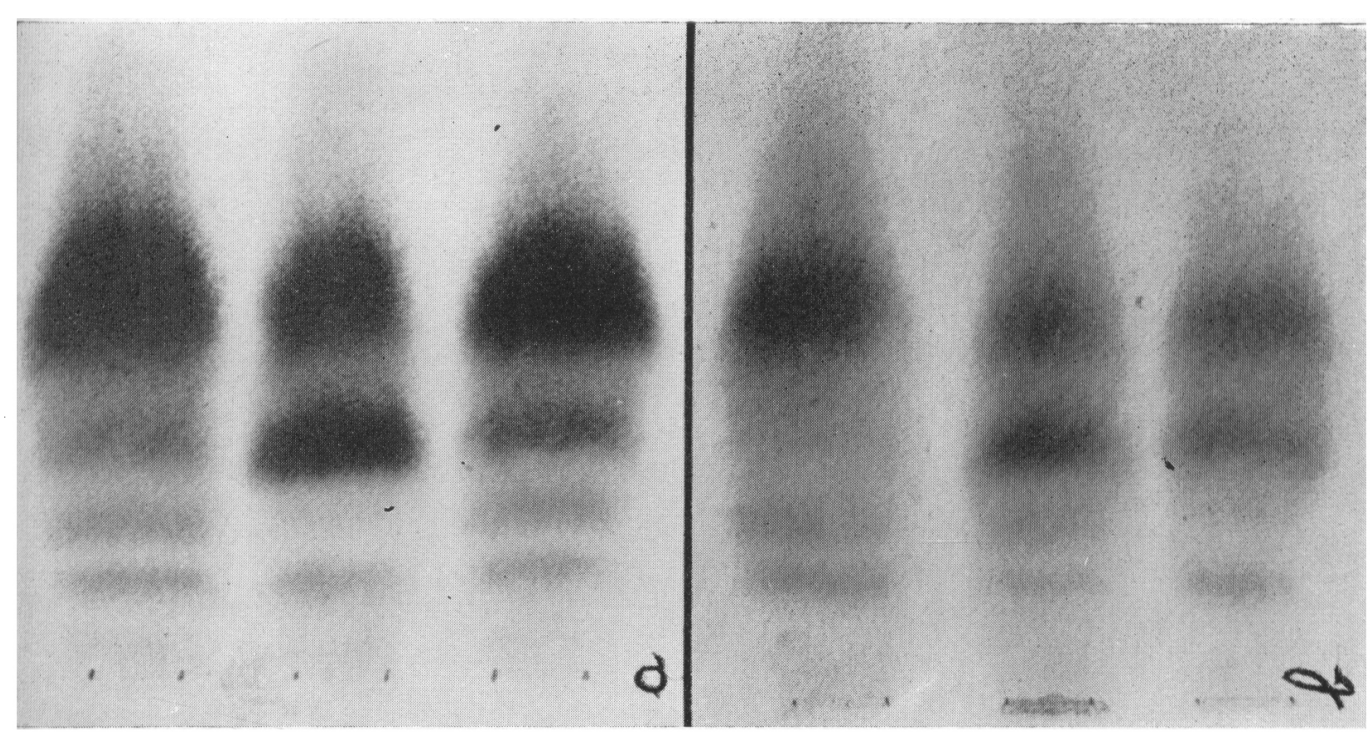

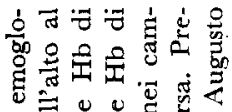

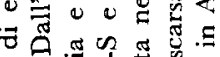

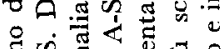

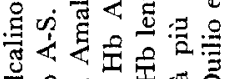
ब过的重

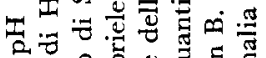

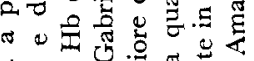

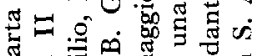
ฮ ว

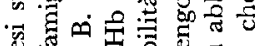

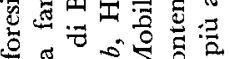
。

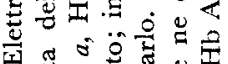

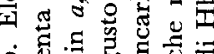
응 है है

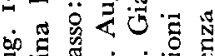

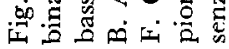
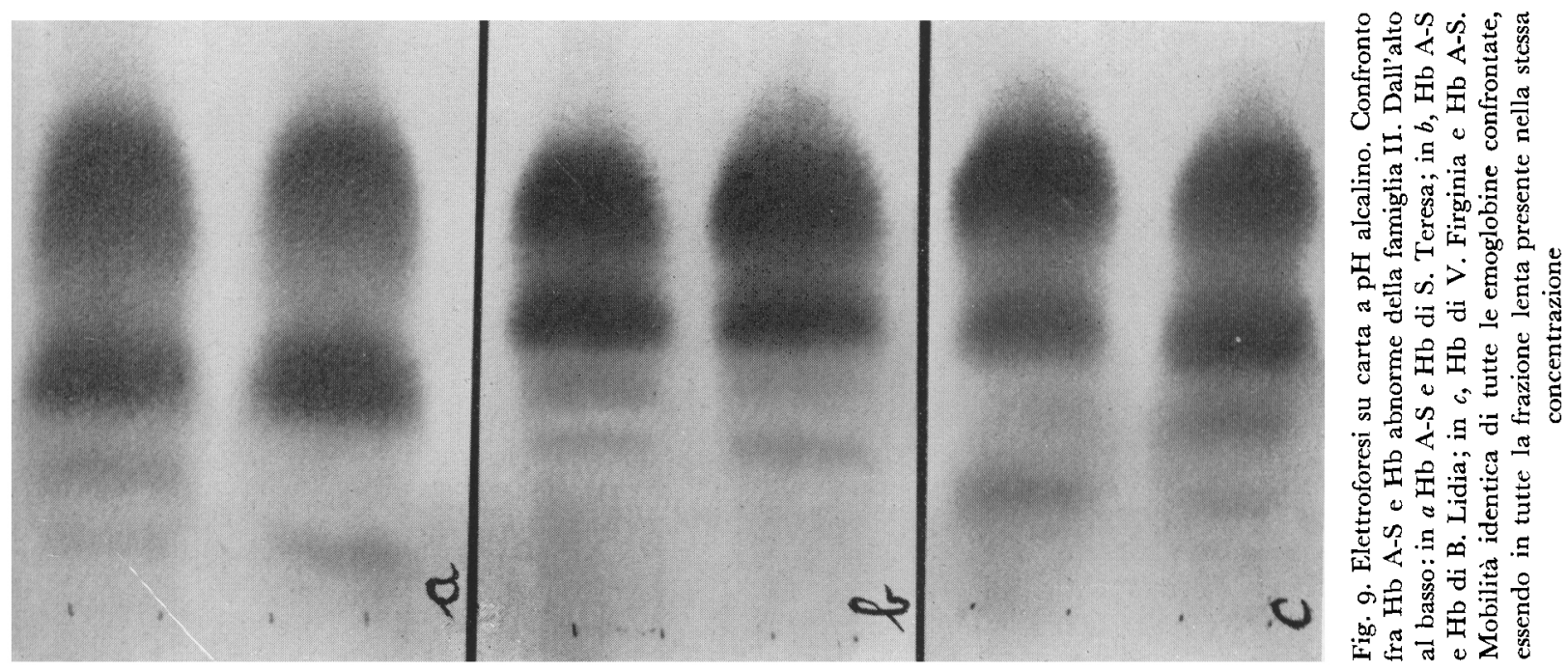
Fig. 14. Elettroforesi su carta a pH alcalino. Confronto di emoglobine lente della famiglia I e II. In alto V. Virginia della famiglia II, in basso G. Ercole della famiglia I. Mobilità del tutto identica delle due emoglobine
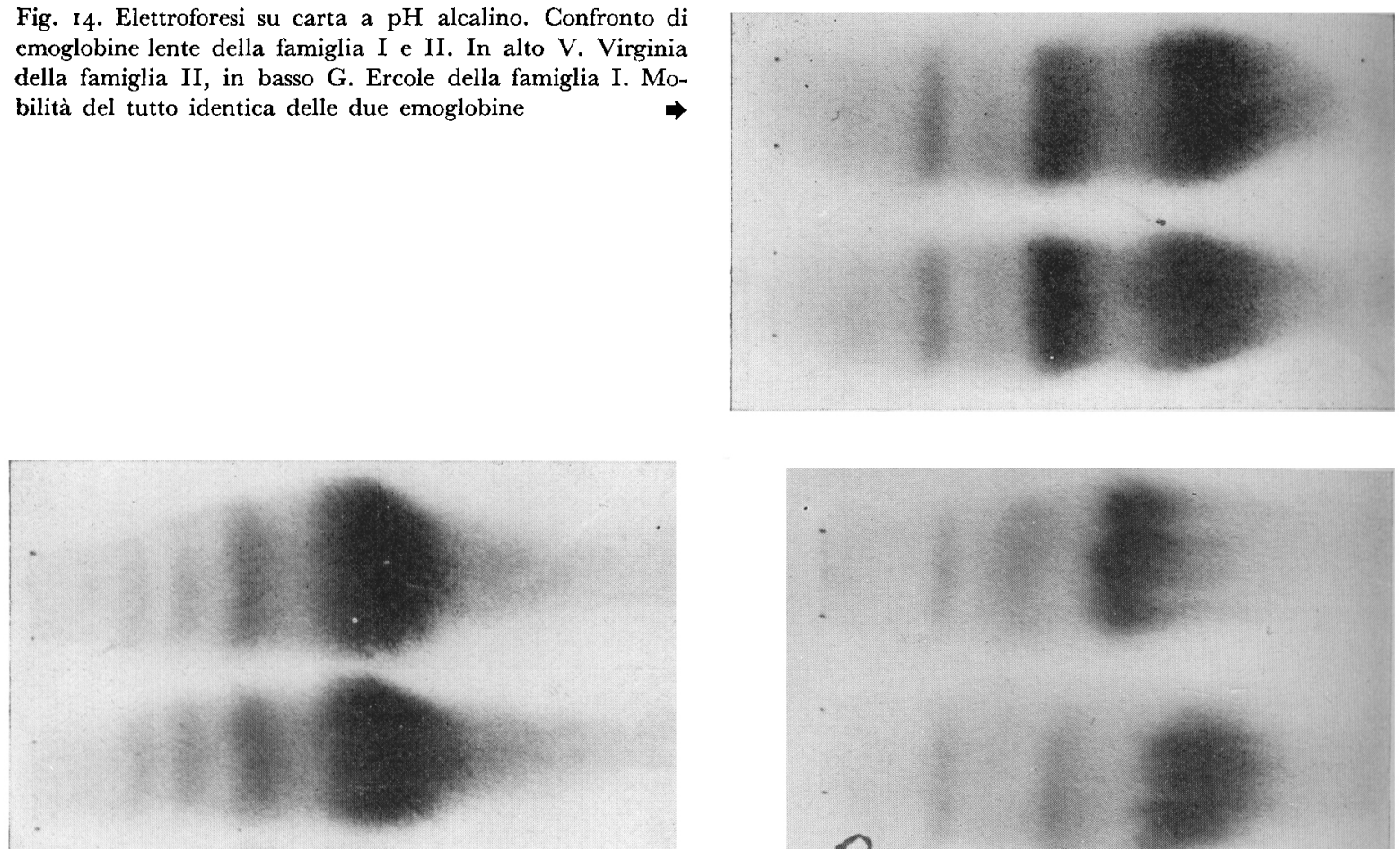

Fig. 12. Elettroforesi su carta a pH alcalino di emoglobine della famiglia. II. In alto S. Amalia con $\mathrm{Hb}$ lenta diluita artificialmente dal 47 al $15 \%$, in basso B. Augusto con $\mathrm{Hb}$ lenta $15 \%$. Mobilità eguale delle due frazioni lente (confronta con a della fig. Io)

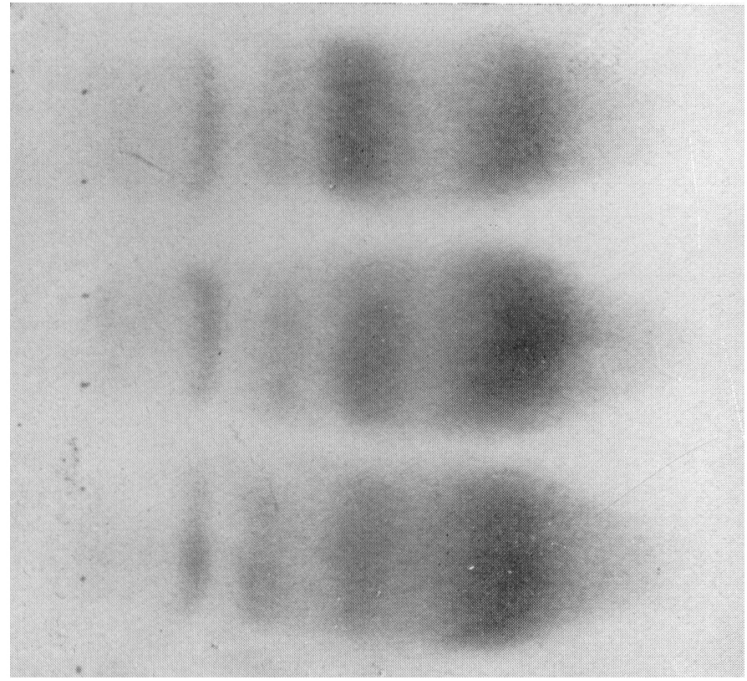

Fig. 13. Elettroforesi su carta a pH alcalino di $\mathrm{Hb}$ lenta della famiglia II e di $\mathrm{Hb} \mathrm{A}$-S. In alto $\mathrm{Hb}$ di $\mathrm{B}$. Lidia contenente il $3 \mathrm{I} \%$ di $\mathrm{Hb}$ lenta, al centro $\mathrm{Hb}$ di $\mathrm{B}$. Lidia con $\mathrm{Hb}$ Ienta diluita al $15 \%$, in basso $\mathrm{Hb} \mathrm{A}-\mathrm{S}$ con quota di $\mathrm{Hb} \mathrm{S}$ diluita al $15 \%$. La mobilità dell'Hb lenta di B. Lidia aumenta col diminuire della sua concentrazione, mentre la mobilità dell'Hb S a bassa concentrazione diviene maggiore di quella dell'Hb lenta di B. Lidia a più forte concentrazione

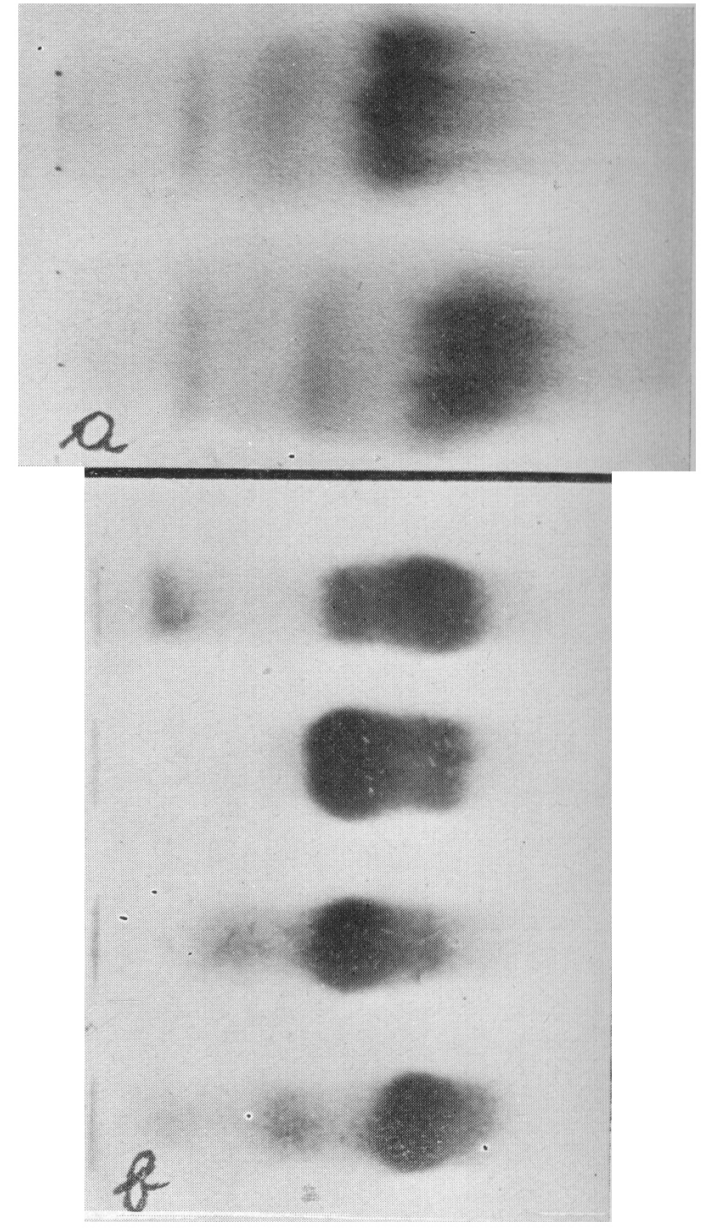

- Fig. 15. Elettroforesi su carta a pH alcalino (a) e su amido solubile Merk a $\mathrm{pH}$ alcalino $(b)$ di $\mathrm{Hb}$ lenta della famiglia II a confronto con $\mathrm{Hb} \mathrm{F}$ e con $\mathrm{Hb}$ di anemia microcitica costituzionale. In $a$ : in alto $\mathrm{Hb}$ di $\mathrm{B}$. Antonella, in basso $\mathrm{Hb}$ di $\mathrm{B}$. Duilio. In $b$ : dall'alto al basso, $\mathrm{Hb} \mathrm{di}$ un caso di anemia microcitica costituzionale, $\mathrm{Hb}$ di cordone ombelicale, $\mathrm{Hb}$ di $\mathrm{B}$. Antonella, $\mathrm{Hb}$ di B. Lidia. Notare la trazione lenta di B. Antonella notevolmente più arretrata di quella degli altri familiari, e la macchia principale di $\mathrm{Hb}$ anch'essa più arretrata dell' $\mathrm{Hb} \mathrm{A}_{1}$ ed esattacon $\mathrm{l}^{\prime} \mathrm{Hb}$ di cordone ombelicale contenente un'altissima quota di $\mathrm{Hb} \mathrm{F}$ e con la $\mathrm{Hb}$ di anemia microcitica costituzionale contenente una più piccola quota di $\mathrm{Hb} \mathrm{F}$ ) mente corrispondente per mobilità all'Hb $\mathrm{F}$ (confrontare 
Tabella I - Dosaggi e quozienti spettrofotometrici delle varie frazioni emoglobiniche nei portatori di Hb lenta e nei loro familiari normali

\begin{tabular}{|c|c|c|c|c|c|c|c|c|c|c|c|}
\hline \multirow{2}{*}{$\begin{array}{l}\text { Num. } \\
\text { progr. }\end{array}$} & \multirow{2}{*}{ Nome e età } & \multirow{2}{*}{ Hb lenta $\%$} & \multirow{2}{*}{$\mathrm{Hb} \mathrm{A}_{2} \%$} & \multirow{2}{*}{$\begin{array}{c}\mathrm{Hb} a-r \\
\text { sull' } \mathrm{Hb} \\
\text { in toto } \%\end{array}$} & \multirow{2}{*}{$\begin{array}{c}\begin{array}{c}\text { Solubilità }(1) \\
\text { dell'Hb }\end{array} \\
\text { in toto gr. } \%\end{array}$} & \multicolumn{2}{|c|}{$\frac{\mathbf{E}_{\mathbf{3 . 0 0 0}} \AA}{\mathbf{E}_{2.800} \AA}$} & \multicolumn{2}{|c|}{$\frac{E_{q \cdot 800} \AA}{E_{4-150} \AA}$} & \multicolumn{2}{|c|}{$\frac{E_{d}}{E_{0} / 2}$} \\
\hline & & & & & & Hb lenta & $\mathrm{Hb} \mathrm{A}_{1}$ & Hb lenta & $\mathrm{Hb} \mathrm{A}_{\mathbf{l}}$ & Hb lenta & $\mathrm{Hb} \mathrm{A}_{1}$ \\
\hline & FAMIGLIA I & & & & & \multirow{6}{*}{0,51} & \multirow{6}{*}{$0,5 \mathrm{I}$} & \multirow{6}{*}{0,26} & \multirow{6}{*}{0,26} & \multirow{6}{*}{0,70} & \multirow{6}{*}{0,72} \\
\hline $\mathbf{1}$ & G. Antonio, a. 59 & ass. & 2,12 & 1,19 & 1,34 & & & & & & \\
\hline 2 & G. Armando, a. 50 & ass. & 2,29 & 1,75 & $\mathrm{I}, 16$ & & & & & & \\
\hline 3 & G. Ludovico, a. 47 & ass. & 2,39 & 1,67 & $\mathrm{I}, 26$ & & & & & & \\
\hline 4 & G. Ercole, a. 43 & 26,5 & $x, 96$ & 1,27 & 1,23 & & & & & & \\
\hline 5 & F. Oriele, a. 39 & ass. & 4,29 & 2,49 & $\mathrm{I}, \mathrm{I} 5$ & & & & & & \\
\hline 6 & G. Servilio, a. $4^{2}$ & 28,3 & $\mathbf{1}, 57$ & $\mathrm{I}, 06$ & 1,16 & \multirow[t]{7}{*}{0,53} & \multirow[t]{7}{*}{$0,5 \mathrm{I}$} & 0,25 & 0,28 & 0,69 & 0,68 \\
\hline 7 & G. Giacomo, a. 28 & ass. & 2,10 & 1,36 & 1,47 & & & & & & \\
\hline 8 & G. Marisa, a. 23 & ass. & 2,59 & 0,99 & $\mathbf{I}, \mathbf{1} 4$ & & & & & & \\
\hline 9 & G. Germano, a. I3 & ass. & 1,93 & $\mathbf{r}, 39$ & 1,17 & & & & & & \\
\hline 10 & G. Franca, a. 19 & 29,4 & & 1,22 & $\mathrm{I}, 4^{\mathrm{I}}$ & & & & & & \\
\hline II & G. Francesca, a. 19 & pres. & & & & & & & & & \\
\hline 12 & G. Franco, a. II & ass. & $2,4^{2}$ & $2,2 \mathrm{I}$ & $\mathrm{I}, \mathbf{0 4}$ & & & & & & \\
\hline & FAMIGLIA II & 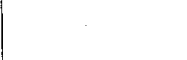 & & & & & & & & & \\
\hline $\mathbf{x}$ & S. Teresa, a. 69 & $4^{8}$ & 1,29 & 1,90 & 1,45 & & & & & & \\
\hline 2 & S. Amalia, a. 66 & 47,6 & 1,45 & $1,6_{3}$ & $\mathrm{I}, \mathrm{r} 6$ & $0,4 \mathrm{I}$ & 0,45 & 0,22 & 0,25 & 0,70 & 0,65 \\
\hline 3 & S. Luigia, a. 59 & ass. & 2,06 & 1,25 & $\mathrm{I}, \mathrm{I} 8$ & & & & & & \\
\hline 4 & V. Ernesta, a. $4^{8}$ & ass. & $\mathbf{I}, 59$ & 1,90 & 1,23 & & & & & & \\
\hline 5 & F. Alberino, a. 42 & ass. & 2,77 & $1,4^{2}$ & $\mathrm{I}, \mathrm{I} 8$ & & & & & & \\
\hline 6 & V. Virginia, a. 39 & 33 & 2,75 & $\mathbf{1}, 33$ & $\mathbf{I}, 41$ & & & & & & \\
\hline 7 & V. Zobeide, a. 35 & ass. & 1,45 & 1,30 & $\mathrm{I}, \mathbf{0 3}$ & & & & & & \\
\hline 8 & V. Delfina, a. 26 & ass. & $2, \mathrm{II}$ & 1,78 & 1,15 & & & & & & \\
\hline 9 & B. Duilio, a. 30 & 15,7 & 3,80 & $\mathrm{I}, 53$ & 1,17 & & & & & & \\
\hline 10 & T. Venerina, a. 26 & ass. & 5,39 & 1,78 & 1,49 & & & & & & \\
\hline II & B. Augusto, a. 27 & 15,2 & 3,60 & 1,05 & 1,25 & 0,39 & $0,4^{8}$ & 0,23 & 0,25 & 0,78 & 0,62 \\
\hline 12 & B. Augusta, a. 25 & ass. & $\mathbf{I}, 99$ & $1,4^{2}$ & 1,19 & & & & & & \\
\hline 13 & F. Giancarlo, a. 20 & 28,7 & $2,5 \mathrm{I}$ & $\mathrm{I}, 64$ & 1,23 & & & & & & \\
\hline $\mathrm{I}_{4}$ & F. Feldino, a. I 4 & ass. & 2,30 & 1,46 & 1,05 & & & & & & \\
\hline 15 & B. Fausto, a. 13 & ass. & $\mathrm{I}, 97$ & 2,25 & $\mathrm{I}, \mathrm{I} 9$ & & & & & & \\
\hline I6 & B. Lidia, a. 7 & 27,6 & 2,35 & $\mathrm{I}, 64$ & & 0,49 & 0,49 & 0,28 & 0,29 & 0,59 & 0,55 \\
\hline 17 & B. Gabriele, a. 2 & 9,7 & $4,5^{2}$ & 2,20 & $\mathrm{r}, 36$ & & & & & . & \\
\hline 18 & B. Antonella, a. & 7,9 & & $74,4^{\circ}$ & & & & & & & \\
\hline 19 & B. Ilario, a. 9 & 22,0 & $\mathbf{I}, 76$ & 1,20 & 1,40 & & & & & & \\
\hline & FAMIGLIA III & & & & & & & & & & \\
\hline I & B. Primo, a. 68 & 30,3 & 1,72 & $\mathbf{I}, 59$ & $\mathrm{I}, 80$ & & & & & & \\
\hline 2 & B. Tebe, a. 35 & 34,2 & 2,43 & 1,25 & $\mathrm{I}, 75$ & & & & & & \\
\hline 3 & B. Antonio, a. $3^{\mathrm{t}}$ & 27,5 & 2,00 & 1,18 & 1,46 & & & & & & \\
\hline 4 & B. Eleonora, a. 26 & 32,7 & $\mathrm{I}, 40$ & $\mathrm{I}, 39$ & 1,56 & $0,5^{\circ}$ & 0,50 & 0,27 & 0,25 & 0,65 & 0,69 \\
\hline 5 & P. Nadia, a. 8 & $3^{6,4}$ & $\mathrm{r}, 4^{\circ}$ & 1,87 & 1,08 & & & & & 0,83 & 0,70 \\
\hline 6 & P. Gianni, a. 5 & 38,2 & $\mathbf{x}, 6 \mathbf{x}$ & $1,3^{8}$ & $\mathbf{I}, 84$ & & & & & & \\
\hline & FAMIGLIA IV & & & & & & & & & & \\
\hline I & Z. Geolinda, a. 49 & I 3,6 & 4,12 & $\mathrm{I}, 20$ & $\mathbf{I}, \mathbf{1} 9$ & & & & & & \\
\hline 2 & C. Odino, a. 49 & ass. & 2,57 & $\mathrm{I}, \mathbf{0 3}$ & $1,5^{2}$ & & & & & & \\
\hline 3 & G. Gina, a. $4^{8}$ & Io,8 & $3,8_{4}$ & 0,88 & $I, 41$ & $0,4^{8}$ & $0,4^{6}$ & 0,29 & 0,25 & $0,7 x$ & 0,55 \\
\hline 4 & M. Livia, a. I 8 & 35,8 & 2,46 & 2,40 & 1,30 & 0,52 & $0,5^{2}$ & 0,26 & 0,26 & $0,8 \mathrm{I}$ & 0,72 \\
\hline 5 & C. Eufemia, a. 27 & 28,7 & 2,61 & 0,95 & 1,31 & 0,49 & $0,5^{\circ}$ & 0,25 & 0,26 & $0,7 \mathbf{I}$ & 0,53 \\
\hline 6 & C. Benita, a. 25 & ass. & 4,76 & 2,14 & 1,39 & & & & & & \\
\hline 7 & C. Maria Pia, a. 22 & ass. & $4,5 \mathrm{I}$ & 1,13 & $1,4^{8}$ & & & & & & \\
\hline & FAMIGLIA V & & & & & & & & & & \\
\hline 1 & A. Roberto, a. 59 & 32,5 & I,55 & $1,5^{6}$ & $\mathrm{I}, 00$ & & & & & & \\
\hline 2 & A. Franca, a. $3 \mathbf{r}$ & 42,6 & $\mathrm{r}, 86$ & $\mathrm{I}, 24$ & $\mathbf{I}, 47$ & & & & & & \\
\hline
\end{tabular}

1 Come ferroemoglobina amorfa in tampone di fosfato $2,60 \mathrm{M}$, ptt $6,8 \mathrm{a}+25^{\circ} \mathrm{C}$, sec. Itano. 


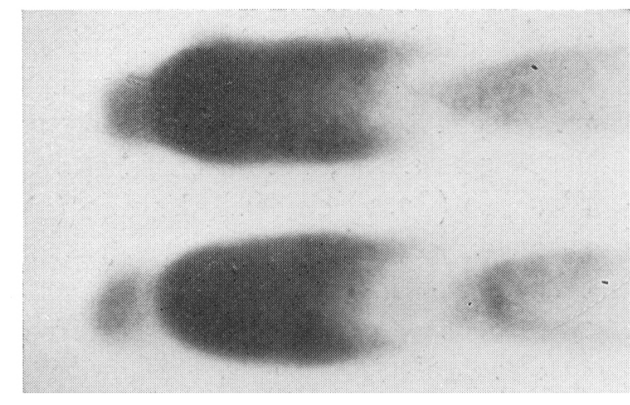

Fig. 16. Elettroforesi su gel d'agar a $\mathrm{pH}$ acido di Hb lenta della I e II famiglia. In alto $\mathrm{Hb}$ di $\mathrm{S}$. Amalia, in basso $\mathrm{Hb}$ di G. Servilio, nelle quali la frazione Jenta è stata diluita al I5\%. Aspetto identico delle due emoglobine

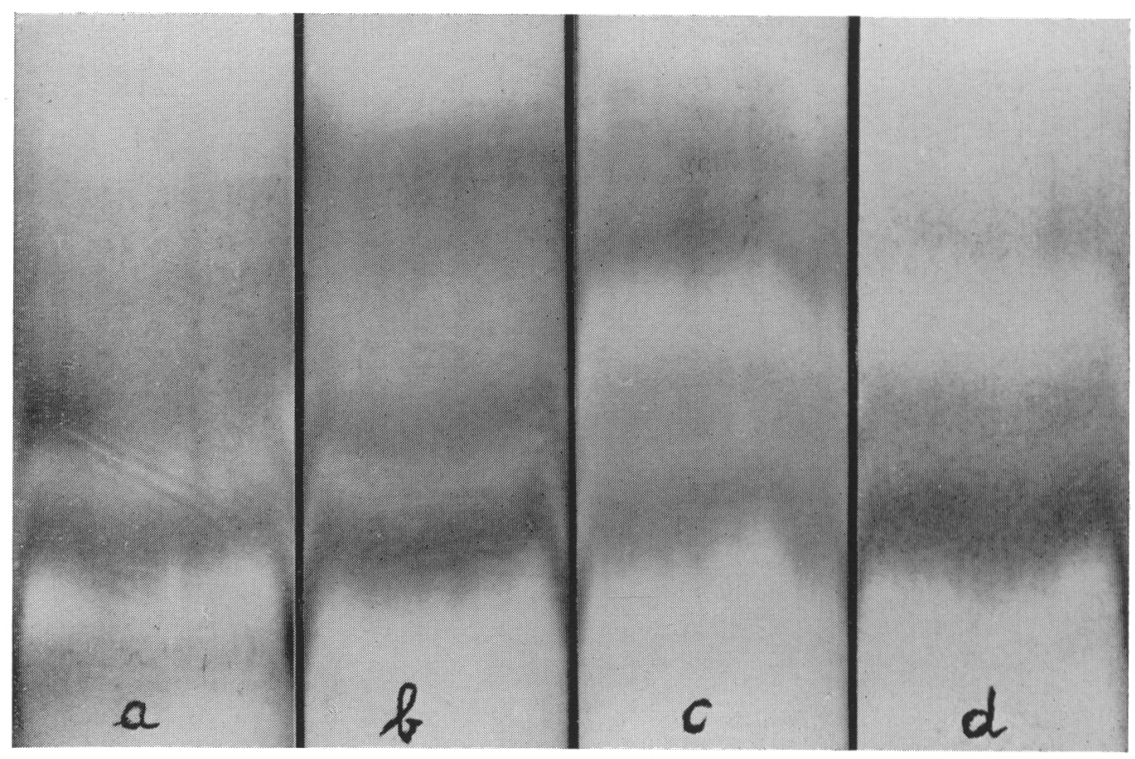

Fig. 17. Cromatografia su Amberlite IRG 50 a $\mathrm{pH}$ acido di Hb lenta della famiglia II e della famiglia I. In $a \mathrm{Hb}$ di B. Duilio, in $b \mathrm{Hb}$ di G. Servilio, in $c \mathrm{Hb}$ di $\mathrm{S}$. Teresa, in $d \mathrm{Hb}$ di $\mathrm{B}$. Ilario. Notare l'assoluta eguaglianza di comportamento dell'Hb lenta in tutti i campioni, la quantità diversa della frazione $\mathrm{L}$ nei diversi soggetti, la frequente suddivisione di questa in due bande, ben visibile per es. in $c$, la netta separazione e visibilità della frazione $A_{2}$ in tutte le emoglobine

$\mathrm{Hb} \mathrm{S}$ (fig. 2) e che non trova riscontro su piastra d'amido, dove il comportamento delle due frazioni è assolutamente identico (fig. 3). La quantità di $\mathrm{Hb}$ lenta è intorno al $30 \%$ in tutti e 4 i soggetti (Tabella $\mathrm{I}$ ), e la mobilità elettroforetica è identica in tutti (v. anche fig. 4). E da rilevare la scarsezza in tutti e 4 i soggetti della quota di $\mathrm{Hb} \mathrm{A} \mathrm{A}_{2}$, la cui macchia è, su carta, visibilmente molto più tenue di quella dei 


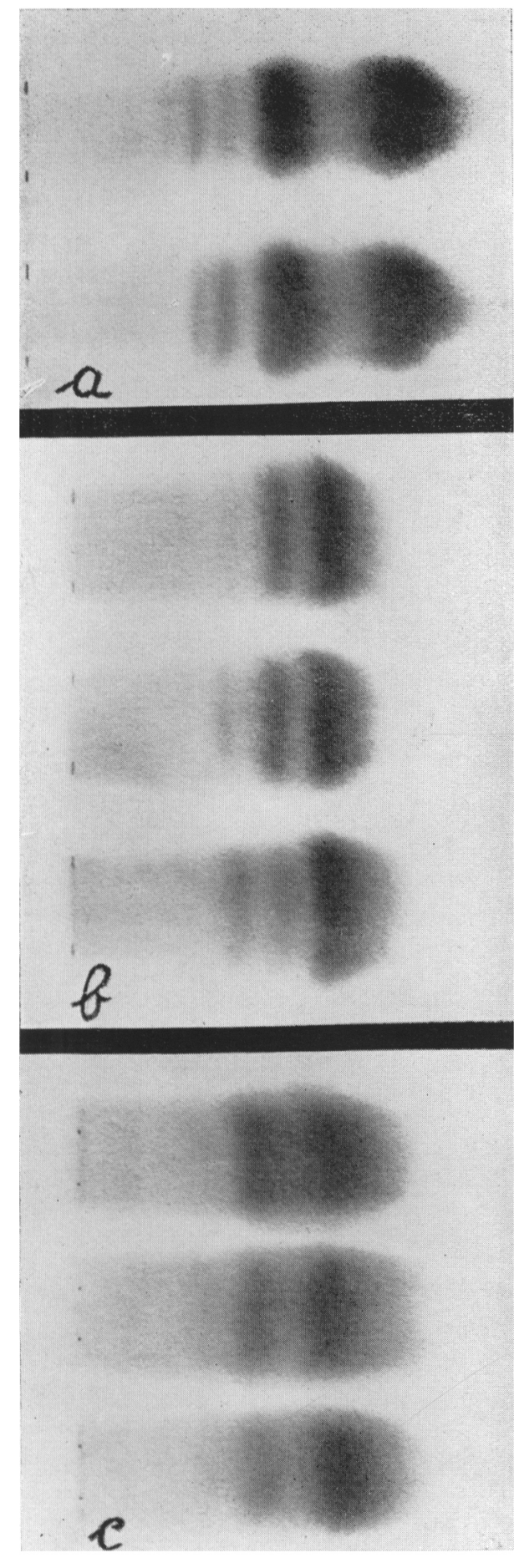

microcitemici (fig. 4), e a cui corrispondono, dopo eluizione da piastra d'amido, valori del tutto normali (Tabella I).

A $\mathrm{pH}$ acido, sia su carta che su piastra d'amido (fig. 5)' e su gel d'amido (fig. 6) non si ha alcuna separazione tra frazione lenta ed $\mathrm{Hb} \mathrm{A}_{1}$. Su gel d'agar viceversa ricompare una separazione pressochè identica a quella dell'Hb A-S (fig. 7). Com'è noto (I3), con questo metodo la mobilità elettroforetica di una frazione emoglobinica è nettamente influenzata dalla sua concentrazione nel miscuglio emoglobinico. Per lo studio comparativo delle emoglobine in esame si è proceduto quindi a paragonare tra loro miscugli aventi originariamente la stessa concentrazione di $\mathrm{Hb}$ lenta (fig. 7) o portati artificialmente ad un'eguale concentrazione. $\mathrm{E}$ in tal modo è risultato appunto che la mobilità di queste emoglobine lente è eguale $\mathrm{a}$ quella dell' $\mathrm{Hb} \mathrm{S}$.

Alla cromatografia su Amberlite IRG-5o la frazione emoglobinica lenta dei 4 soggetti presenta mobilità notevolmente inferiore a quella dell'Hb S (fig. 8). E visibile, inoltre, ben distintamente in G. Franca e meno distintamente in G. Servilio, una suddivisione della frazione lenta in due bande, che si manifesta protraendo la cromatografia per 24 ore.

Lo studio spettrofotometrico nell'U.V. dimostra che la frazione lenta ha una curva di assorbimento del tutto identica a quella dell'Hb $A_{1}$. I rapporti $\frac{E_{3 \cdot 000} \AA}{E_{2 \cdot 800} \AA}$ e $\frac{E_{2 \cdot 800} \AA}{E_{4 \cdot 150} \AA}$ sono

Fig. 18. Elettroforesi su carta a pH alcalino. Confronto fra $\mathrm{Hb}$ lenta della famiglia III, Hb A-S, Hb A-L delle precedenti famiglie e $\mathrm{Hb} \mathrm{A}-\mathrm{D}$. Dall'alto al basso: in $a$, $\mathrm{Hb}$ di B. Antonio e $\mathrm{Hb} \mathrm{A}-\mathrm{S}$; in $b, \mathrm{Hb}$ di G. Franca, B. Eleonora e B. Lidia; in $c, \mathrm{Hb}$ di S. Amalia, B. Primo e Hb A-D. Uguaglianza di mobilità dell'Hb lenta della famiglia III con l'Hb S, l'Hb L e l'Hb D 

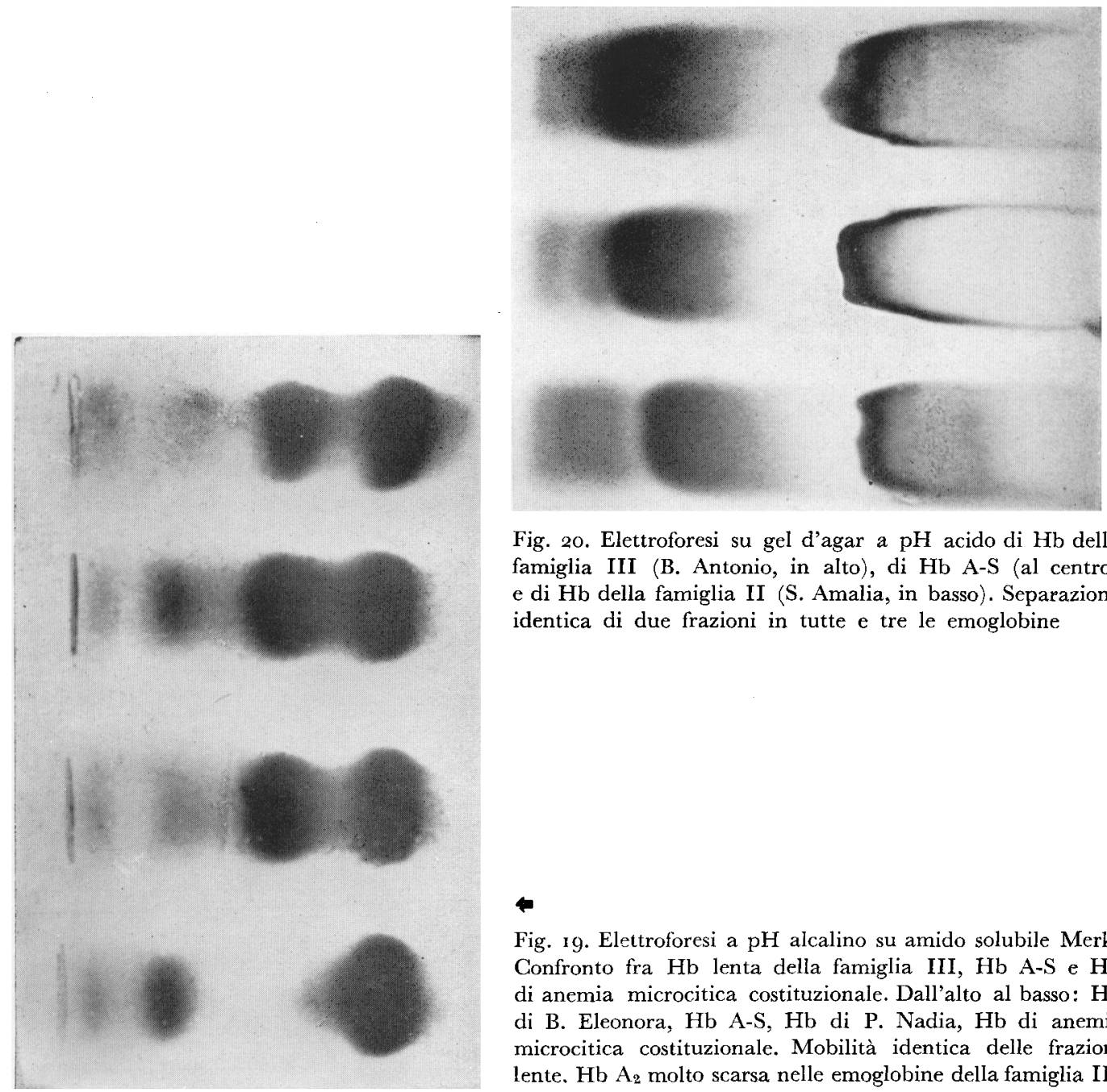

Fig. 2o. Elettroforesi su gel d'agar a $\mathrm{pH}$ acido di $\mathrm{Hb}$ della famiglia III (B. Antonio, in alto), di $\mathrm{Hb} \mathrm{A}-\mathrm{S}$ (al centro) e di $\mathrm{Hb}$ della famiglia II ( $\mathrm{S}$. Amalia, in basso). Separazione identica di due frazioni in tutte e tre le emoglobine

Fig. 19. Elettroforesi a pH alcalino su amido solubile Merk. Confronto fra $\mathrm{Hb}$ lenta della famiglia III, $\mathrm{Hb} \mathrm{A}-\mathrm{S}$ e $\mathrm{Hb}$ di anemia microcitica costituzionale. Dall'alto al basso: $\mathrm{Hb}$ di B. Eleonora, $\mathrm{Hb} \mathrm{A}-\mathrm{S}, \mathrm{Hb}$ di P. Nadia, $\mathrm{Hb}$ di anemia microcitica costituzionale. Mobilità identica delle frazioni lente. $\mathrm{Hb} \mathrm{A}_{2}$ molto scarsa nelle emoglobine della famiglia III

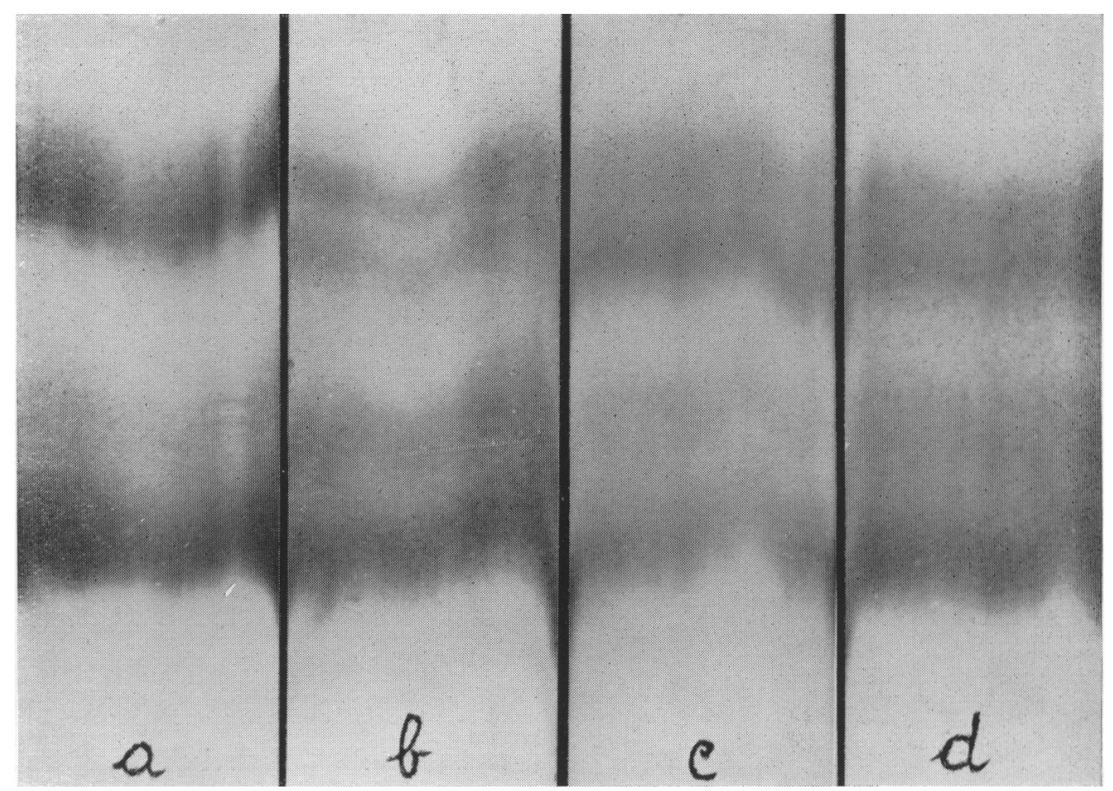

Fig. 2r. Cromatografia su Amberlite IRC 50 a pH acido di emoglobine della famiglia II e della famiglia III. In $a \mathrm{Hb}$ di $\mathrm{B}$. Tebe, in $b \mathrm{Hb}$ di $\mathrm{B}$. Primo, in $c \mathrm{Hb}$ di $\mathrm{S}$. Teresa, in $d \mathrm{Hb}$ di $\mathrm{B}$. Antonio. Mobilità della frazione lenta della famiglia III identica a quella della frazione L della famiglia II. Ben visibile in alcune emoglobine la presenza di due bande di $\mathrm{Hb} \mathrm{L} . \mathrm{Hb} \mathrm{A_{2 }}$ sempre ben separata dall'A $\mathrm{A}_{1}$ e ben visibile 

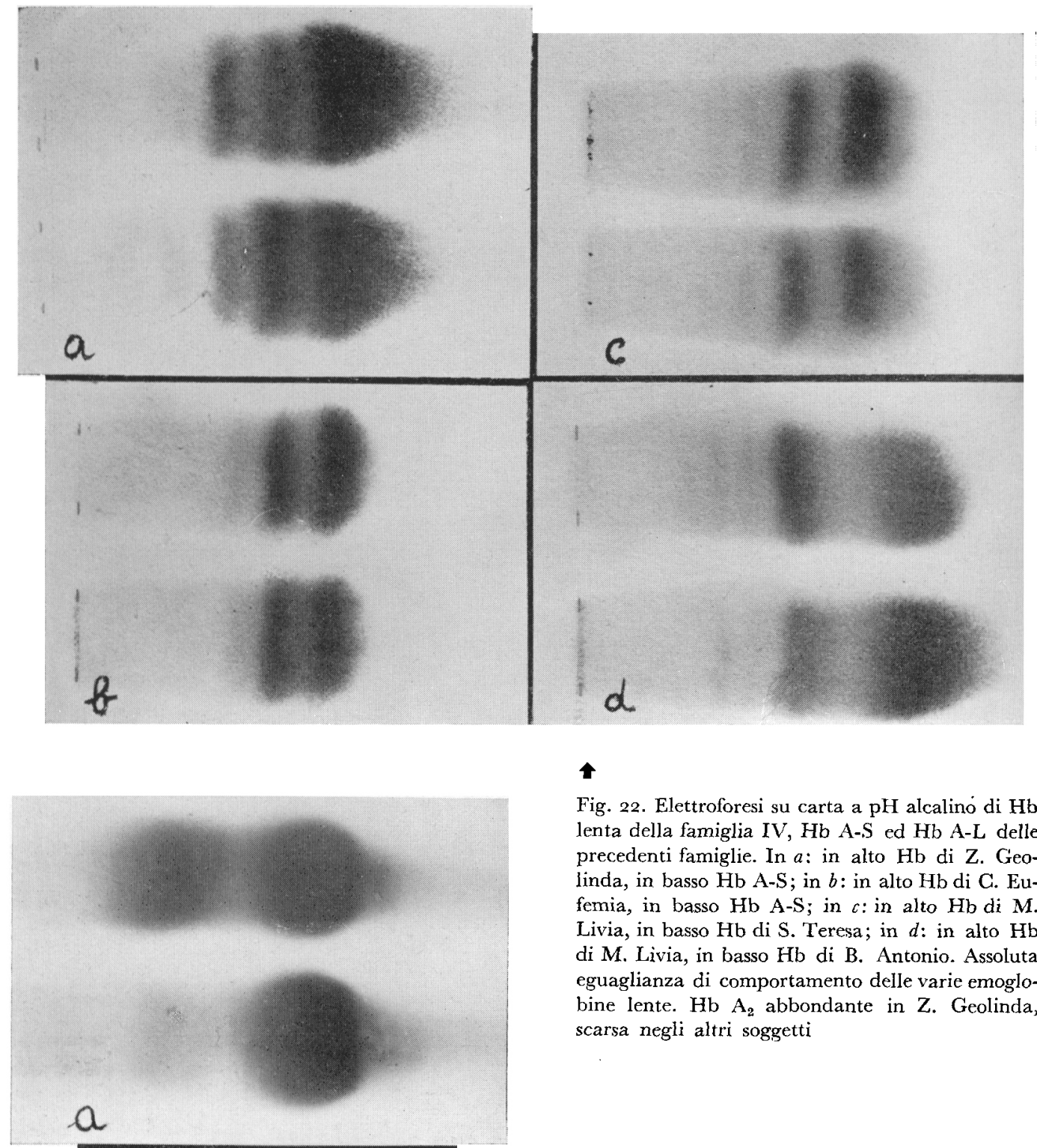

Fig. 22. Elettroforesi su carta a $\mathrm{pH}$ alcalino di $\mathrm{Hb}$ lenta della famiglia $\mathrm{IV}, \mathrm{Hb}$ A-S ed $\mathrm{Hb}$ A-L delle precedenti famiglie. In $a$ : in alto $\mathrm{Hb}$ di $\mathrm{Z}$. Geolinda, in basso $\mathrm{Hb} \mathrm{A-S}$; in $b$ : in alto $\mathrm{Hb}$ di C. Eufemia, in basso $\mathrm{Hb} \mathrm{A}-\mathrm{S}$; in $c$ : in alto $\mathrm{Hb}$ di $M$. Livia, in basso $\mathrm{Hb}$ di $\mathrm{S}$. Teresa; in $d$ : in alto $\mathrm{Hb}$ di M. Livia, in basso $\mathrm{Hb}$ di B. Antonio. Assoluta eguaglianza di comportamento delle varie emoglobine lente. $\mathrm{Hb} \mathrm{\textrm {A } _ { 2 }}$ abbondante in $\mathrm{Z}$. Geolinda, scarsa negli altri soggetti

Fig. 23. Elettroforesi a $\mathrm{pH}$ alcalino su piastra d'amido $(a)$, e su carta $(b)$, di emoglobine delle famiglie II e IV. Dall'alto al basso: in $a \mathrm{Hb}$ di $\mathbf{B}$. Primo e di Z. Geolinda; in $b \mathrm{Hb}$ di Z. Gina, $\mathrm{Hb}$ normale, $\mathrm{Hb}$ di $\mathrm{C}$. Eufemia. Mobilità lievemente maggiore della frazione lenta quando la sua concentrazione è bassa. Presenza in $\mathrm{Z}$. Geolinda $\mathrm{e}$ Gina di $\mathrm{Hb} \mathrm{A}_{\mathbf{2}}$ più abbondante che negli altri soggetti 
normali per ambedue le frazioni (Tabella I) e anche la denaturazione alcalina della frazione lenta si compie entro $60^{\prime \prime}$, come quella dell' $\mathrm{Hb} \mathrm{A}_{1}$. La quantità di $\mathrm{Hb} a-r$ è in tutti i soggetti entro i limiti normali (Tabella I).

Famiglia II - Anche in questa famiglia la frazione emoglobinica lenta, presente in 12 membri, dimostra all'elettroforesi su carta a pH alcalino, mobilità assolutamente identica a quella dell' $\mathrm{Hb} \mathrm{S}$ (fig. 9). In questi soggetti però la quota di $\mathrm{Hb}$ lenta è fortemente variabile, oscillando dal 45-50\% al 10-I $5 \%$ (Tabella I): e si è osservato pertanto, paragonando all'elettroforesi su carta (fig. Io), e su amido (fig. I I), emoglobine contenenti quote diverse di frazione lenta che quanto più bassa è la

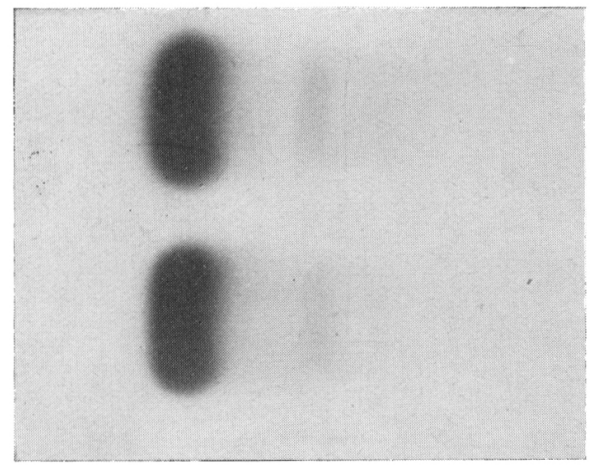

Fig. 24. Elettroforesi su gel d'amido a pH acido di $\mathrm{Hb}$ della famiglia IV: in alto C. Benita (microcitemica), in basso C. Eufemia ( $\mathrm{Hb}$ lenta). Aspetto eguale delle due emoglobine, senza nessun frazionamento

Fig. 25. Elettroforesi su gel d'agar a pH acido di $\mathrm{Hb}$ lenta della famiglia IV (Z. Geolinda, in alto), della famiglia I (G. Servilio, al centro), e della famiglia II (S. Amalia, in basso), nelle quali la frazione lenta è stata diluita al $15 \%$. Aspetto identico delle tre emoglobine

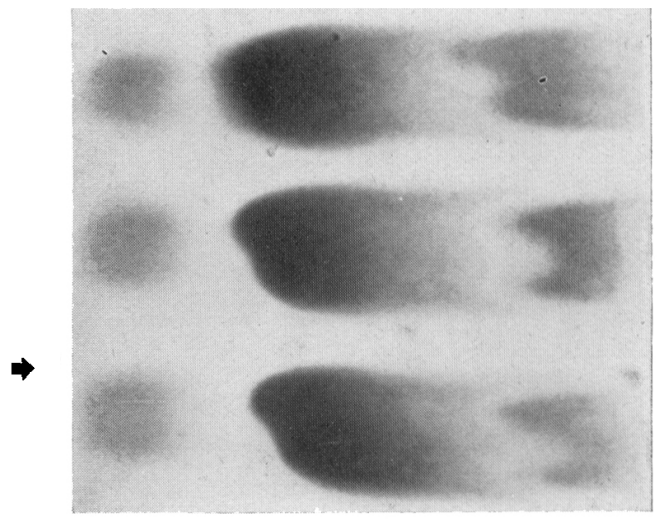

concentrazione della frazione lenta, tanto maggiore è la sua mobilità. La conferma che la differenza di mobilità, osservata per esempio (fig. Io) fra la madre e due suoi figli, è determinata esclusivamente dalla differente concentrazione della frazione lenta, è data dal fatto che portando la concentrazione di Hb lenta della madre allo stesso valore di quella del figlio, la mobilità elettroforetica diviene eguale (fig. I2) e viceversa riducendo al $\mathrm{I}_{5} \%$ la quota di $\mathrm{Hb}$ lenta di uno di questo soggetti e la quota di $\mathrm{Hb} \mathrm{S}$ di un falcemico, in questi due miscugli la mobilità delle frazioni lente risulta eguale, ma nello stesso tempo nettamente maggiore della mobilità della frazione lenta dell' $\mathrm{Hb}$ originaria del soggetto, che ha la concentrazione del $30 \%$ circa (fig. I3). La mobilità elettroforetica a $\mathrm{pH}$ alcalino dell'Hb lenta presente in questa famiglia è assolutamente identica a quella dell'Hb lenta della famiglia precedente (fig. I4). 
Un comportamento elettroforetico diverso da quello degli altri membri portatori di $\mathrm{Hb}$ lenta è stato osservato invece nella bambina $\mathrm{B}$. Antonella, nella quale, oltre alla presenza di una forte quota di $\mathrm{Hb} a-r(74 \%)$ che determina un arretramento della macchia principale di $\mathrm{Hb}$ rispetto all' $\mathrm{Hb} \mathrm{A}_{1}$, si nota un notevole e costante arretramento anche dell' $\mathrm{Hb}$ lenta, la quale appare ben divisa dall' $\mathrm{Hb}$ principale e localizzata (fig. I5) fra l'Hb lenta e l'Hb $\mathrm{A}_{2}$ degli altri soggetti.

$\mathrm{Nei}$ riguardi dell' $\mathrm{Hb} \mathrm{A}_{2}$ è da segnalare il reperto nei 12 membri portatori di $\mathrm{Hb}$ lenta, di quote indifferentemente alte o basse di $\mathrm{Hb} \mathrm{A}_{2}$ (Tabella I) senza rapporto

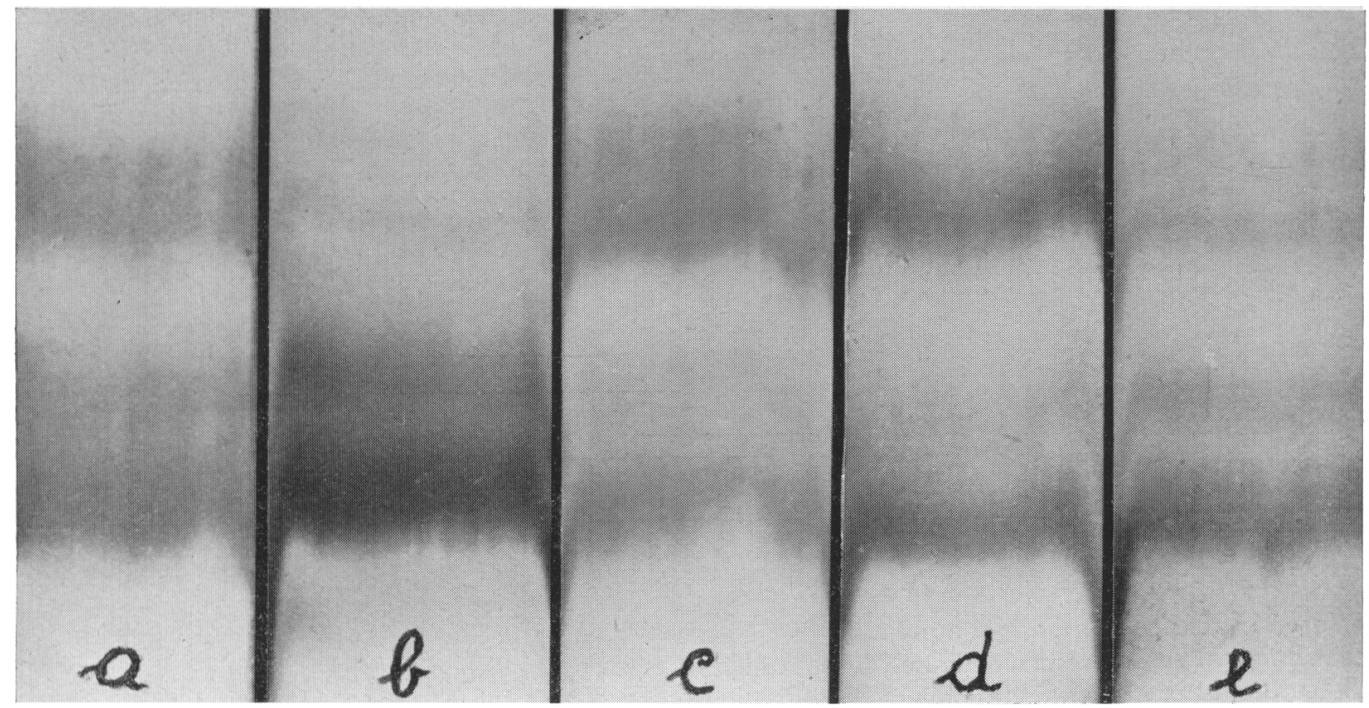

Fig. 26. Cromatografia su Amberlite IRG $5^{\circ}$ a $\mathrm{pH}$ acido. Confronto fra $\mathrm{Hb}$ lenta della famiglia IV ed $\mathrm{Hb}$ lenta delle famiglie precedenti. In $a \mathrm{Hb}$ di $\mathrm{B}$. Antonio, in $b \mathrm{Hb}$ di $\mathrm{Z}$. Geolinda, in $c \mathrm{Hb}$ di $\mathrm{S}$. Teresa, in $d \mathrm{Hb}$ di M. Livia, in $e \mathrm{Hb}$ di G. Franca. Identico comportamento dell'Hb nelle 4 lamiglie. Presenza di due bande di $\mathrm{Hb} \mathrm{L}$ anche in qualche membro della famiglia IV (per es. $b$ ). $\mathrm{Hb} \mathrm{A}_{2}$ ben visibile in tutti, più abbondante in Z. Geolinda $(b)$

con l'intensità degli altri caratteri microcitemici. Il dato è ben riconoscibile all'esame delle carte elettroforetiche (figg. 4-9-I0-I 2-I3) ed è documentato poi dall'esame quantitativo (Tabella I), il quale mette in evidenza, per esempio, che nelle due capostipiti (S. Amalia e S. Teresa) la quota di $\mathrm{Hb} \mathrm{\textrm {A } _ { 2 }}$ è bassa, mentre fra i loro discendenti alcuni hanno una quota bassa e altri elevata.

A pH acido sia su carta che su amido (figg. 5-6) l'Hb lenta di questi soggetti non si divide dall'Hb $A_{1}$. Su gel d'agar viceversa si divide in due frazioni con mobilità identica a quella dell'Hb della famiglia I (fig. I6).

Alla cromatografia su Amberlite IRC-50 la frazione emoglobinica lenta presenta mobilità identica a quella della famiglia I, e la stessa divisione in due bande (fig. I 7). 


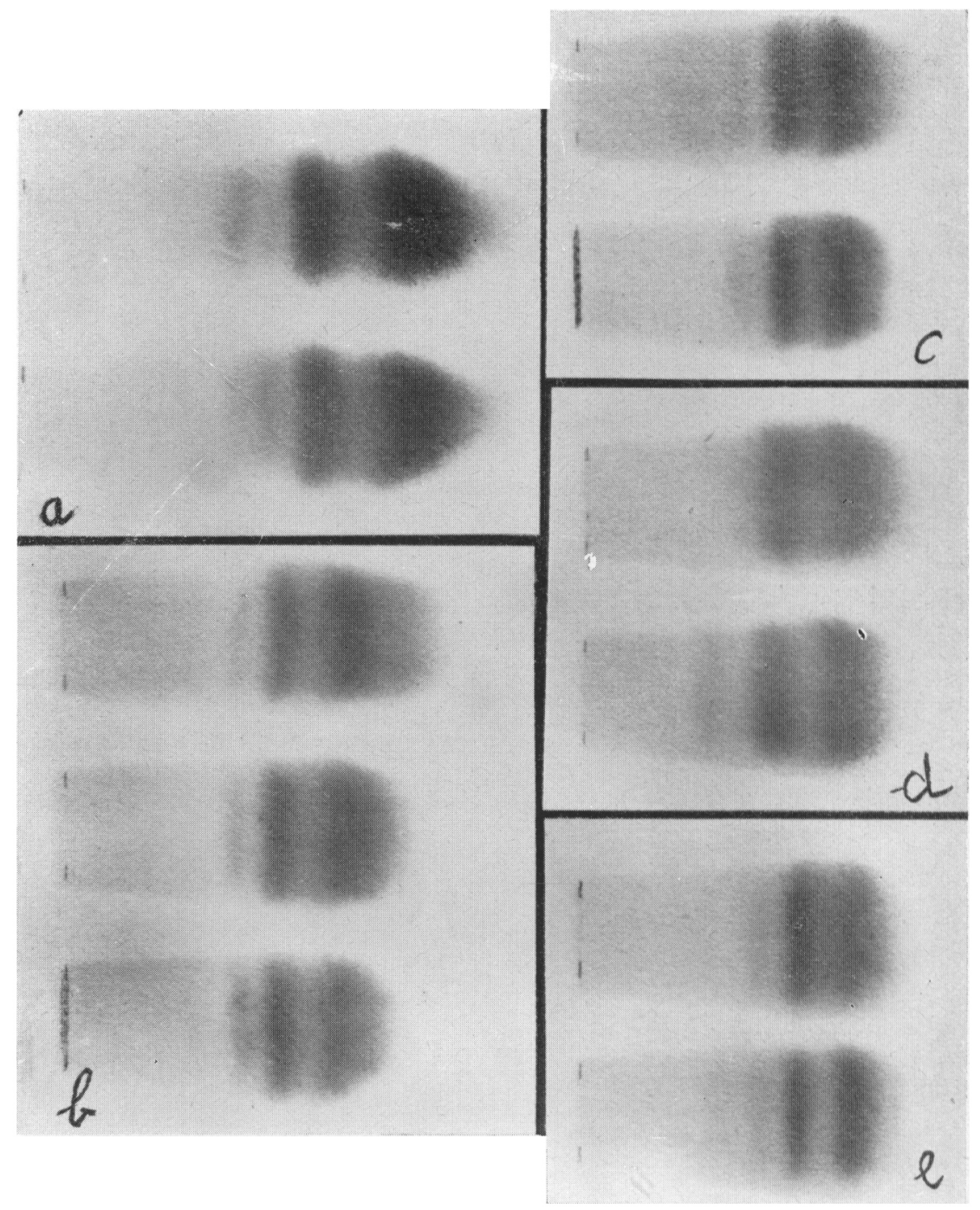

Fig. 27. Elettroforesi su carta a pH alcalino. Confronto fra $\mathrm{Hb}$ lenta della famiglia $\mathrm{V}$, $\mathrm{Hb} \mathrm{A}-\mathrm{S}, \mathrm{Hb} \mathrm{A}-\mathrm{D}, \mathrm{Hb} \mathrm{A}-\mathrm{I}$ delle precedenti famiglie. In $a$ : in alto $\mathrm{Hb}$ di A. Franca, in basso $\mathrm{Hb} \mathrm{A}-\mathrm{S}$; in $b$ : in alto $\mathrm{Hb} \mathrm{A}-\mathrm{D}$ [osservazione precedentemente pubblicata (30)], al centro $\mathrm{Hb}$ di A. Roberto, in basso $\mathrm{Hb} \mathrm{A}-\mathrm{S}$; in $c$ : in alto Hb A-L (G. Franca), in basso $\mathrm{Hb}$ di A. Roberto; in $d$ : in alto $\mathrm{Hb}$ di A. Franca, in basso $\mathrm{Hb} \mathrm{A-L} \mathrm{(B.} \mathrm{Eleonora);} \mathrm{in}$ $e$ : in alto $\mathrm{Hb}$ di A. Roberto, in basso $\mathrm{Hb}$ A-I. (M. Livia). Identica mobilità elettroforetica dell'Hb della famiglia $\mathrm{V}$, dell'Hb A-S, dell'Hb A-L e dell'Hb A-D del ceppo familiare precedentemente illustrato $(30)$ 


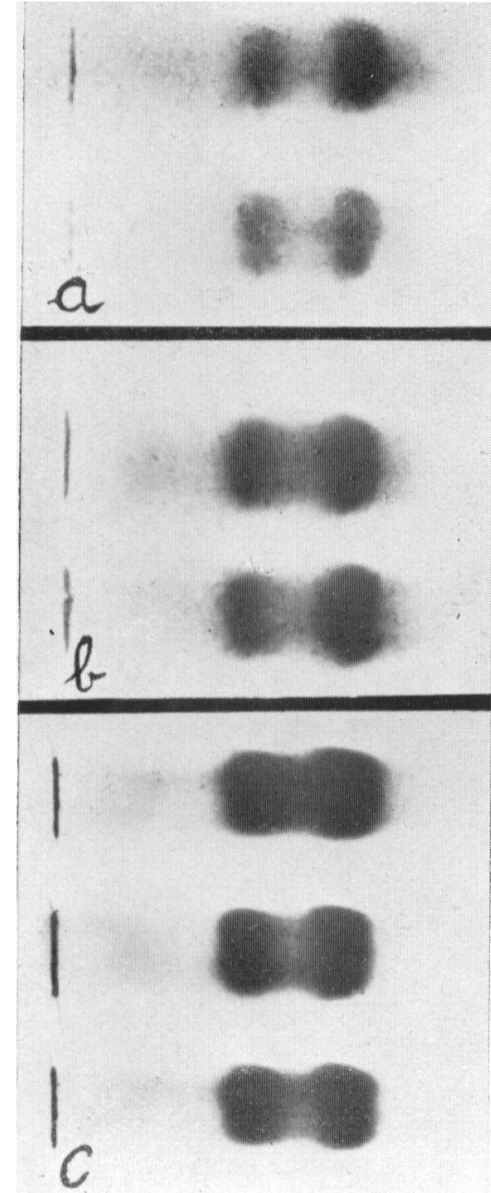

Fig. 28. Elettroforesi a pH alcalino su amido solubile Merk. Identica mobilità elettroforetica dell'Hb della famiglia $\mathrm{V}$, dell' $\mathrm{Hb}$ A-S, dell'Hb A-L e dell'Hb A-D del ceppo precedentemente pubblicato $(30)$. Dall'alto in basso: in $a \mathrm{Hb}$ di A. Franca e $\mathrm{Hb} \mathrm{A}-\mathrm{L}$ (B. Antonio); in $b \mathrm{Hb} \mathrm{A}-\mathrm{S}$ e $\mathrm{Hb}$ di A. Roberto; in $6 \mathrm{Hb} \mathrm{A}-\mathrm{D}, \mathrm{Hb}$ di A. Franca, Hb di A. Roberto

Fig. 30. Elettroforesi su gel d'agar a pH acido di emoglobine diverse. Dall'alto al basso: in $a \mathrm{Hb} \mathrm{di}$ A. Franca, Hb di G. Servilio, Hb $\mathrm{A}-\mathrm{S}$; in $b \mathrm{Hb}$ di B. Antonio, $\mathrm{Hb}$ di $\mathrm{A}$. Roberto, $\mathrm{Hb}$ normale. Mancanza nelle due emoglobine della famiglia $\mathrm{V}$, di separazione in due frazioni; aspetto del tutto identico a quello dell'Hb normale

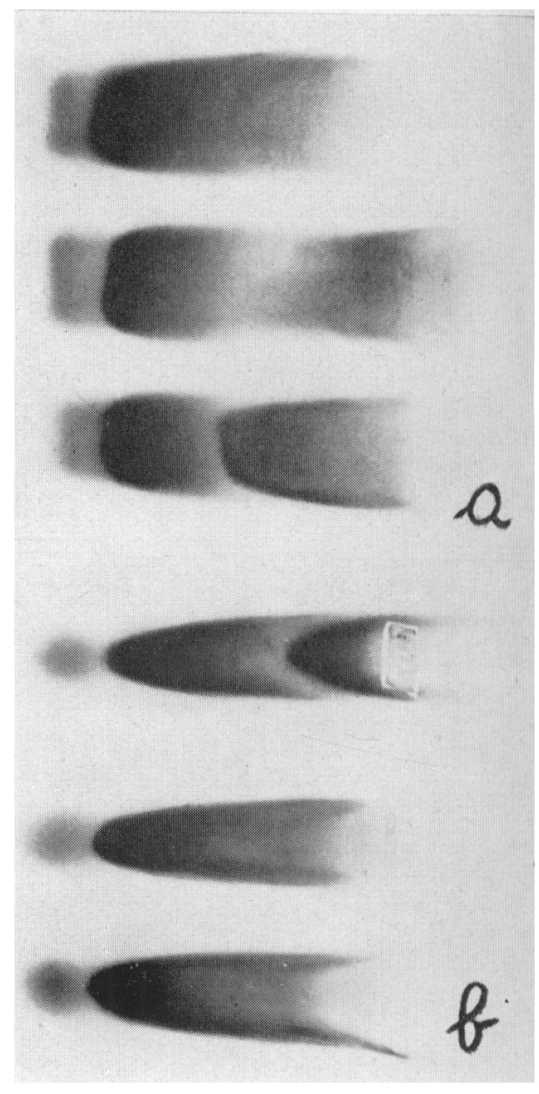

Fig. 29. Elettroforesi su gel d'amido a $\mathrm{pH}$ acido di $\mathrm{Hb} \mathrm{A}-\mathrm{S}$ (al centro) e di emoglobina della famiglia $V$ (in alto A. Franca, in basso A. Roberto). Aspetto identico delle tre emoglobine, senza alcun frazionamento

Fig. 31. Elettroforesi su gel d'agar a pH acido di emoglobine diverse. Dall'alto al basso: Hb della famiglia V (A. Franca), $\mathrm{Hb}$ A-D precedentemente pubblicata (30), $\mathrm{Hb}$ normale, Hb A-L (P. Nadia). Aspetto del tutto identico delle tre prime emoglobine

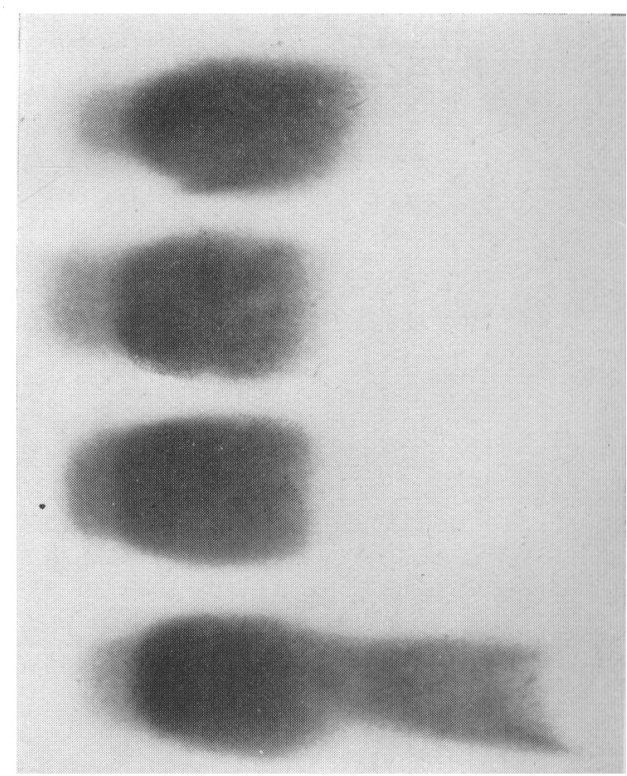


Le curve di assorbimento nell'U.V. hanno aspetto del tutto normale per ambedue le frazioni, e così pure $\mathrm{i}$ quozienti $\frac{\mathrm{E}_{3 \cdot 000} \AA}{\mathrm{E}_{2 \cdot 800} \AA} \mathrm{e} \frac{\mathrm{E}_{2 \cdot 800} \AA}{\mathrm{E}_{4 \cdot 150} \AA}$ sono normali in entrambe. La denaturazione dell'Hb lenta si compie come quella dell' $\mathrm{Hb}$ normale entro $6 \mathrm{o}^{\prime \prime}$, e così pure la quantità totale di $\mathrm{Hb} a-r$ risulta in tutti i soggetti, salvo $\mathrm{B}$. Antonella, al di sotto del $2,5 \%$ (Tabella I).

Famiglia III - L'Hb lenta presente nei membri di questa famiglia ha mobilità elettroforetica a $\mathrm{pH}$ alcalino identica a quella dell' $\mathrm{Hb} \mathrm{S}$ e a quella dell' $\mathrm{Hb}$ lenta delle

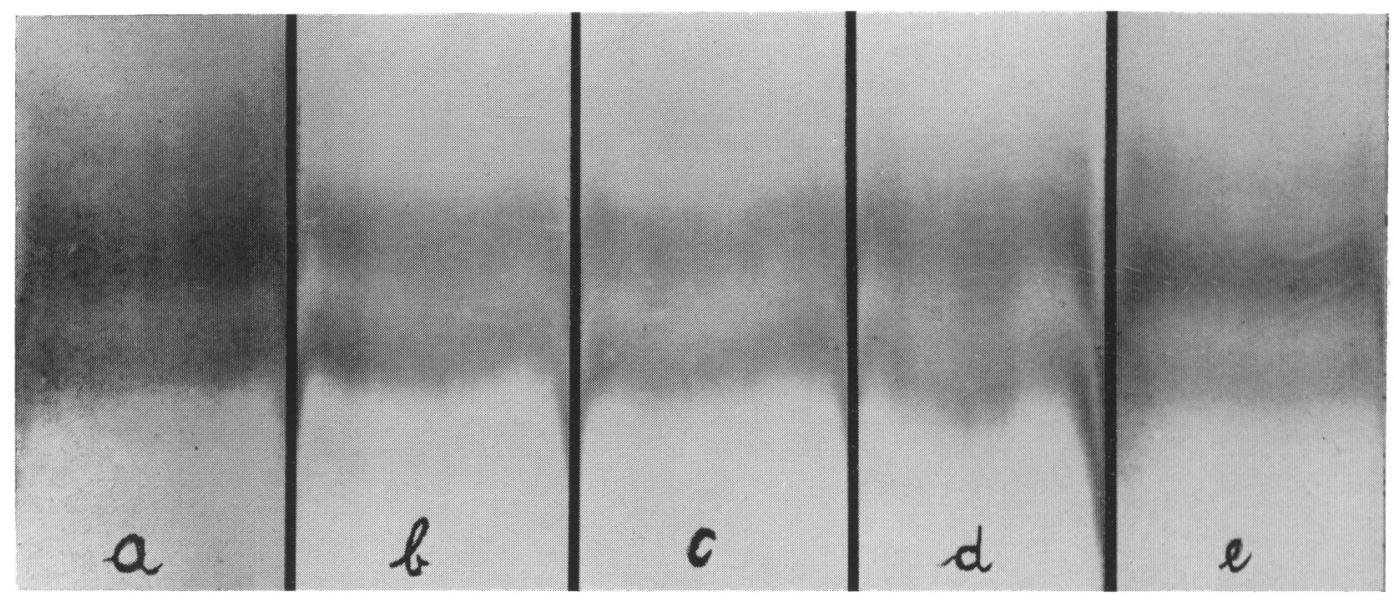

Fig. 32. Cromatografia su Amberlite IRC 50 a pH acido. Confronto dell'Hb della famiglia $\mathrm{V}$ con $\mathrm{Hb} \mathrm{A}-\mathrm{D}$ e con $\mathrm{Hb} \mathrm{A}-\mathrm{S}$. In $a$ : $\mathrm{Hb} \mathrm{A}-\mathrm{D}$ di precedente osservazione (30); in $b \mathrm{Hb}$ di $\mathrm{A}$. Roberto; in $c \mathrm{Hb} \mathrm{A}-\mathrm{S}$; in $d \mathrm{Hb}$ di A. Franca, in $e$ altra $\mathrm{Hb} \Lambda$-D di precedente osservazione. Assoluta eguaglianza di comportamento di tutte le emoglobine; frazione lenta dell' $\mathrm{Hb}$ della famiglia $\mathrm{V}$ perfettamente allineata alla frazione $\mathrm{S}$ e alla frazione, $\mathrm{D}$

precedenti famiglie (figg. I8-Ig). La concentrazione della frazione lenta è pressochè uniforme in tutti i soggetti, oscillando solo dal 27 al $38 \%$ (Tabella I). La quota di $\mathrm{Hb}_{2}$ è normale in tutti $\mathrm{i}$ casi e così pure la quota di $\mathrm{Hb} a-r$ non supera in nessuno il $2 \%$ (Tabella I).

A pH acido su carta, su piastra d'amido e su gel d'amido (figg. 5-6) l'Hb lenta non si divide dall' $\mathrm{Hb}_{1}$. Su gel d'agar si divide invece dall' $\mathrm{Hb} \mathrm{A}_{1}$ (fig. 20) con mobilità praticamente identica a quella dell'Hb $\mathrm{S}$ e dell'Hb lenta delle precedenti famiglie.

Alla cromatografia su Amberlite IRG-5o l'Hb lenta ha la stessa mobilità di quella delle famiglie precedenti (fig. 2 I) e in qualche soggetto presenta la stessa suddivisione in due bande.

L'esame nell'U.V. della frazione lenta mostra un comportamento della curva di assorbimento identico a quello dell' $\mathrm{Hb}_{1}$, e alla prova della denaturazione alcalina questa frazione risulta completamente denaturata entro $90^{\prime \prime}$. 
Un ultimo particolare da segnalare nei portatori di Hb lenta di questa famiglia, riguarda la presenza nel blocco d'amido, al termine della elettroforesi di un'Hb lenta, di una piccola macchia tenuemente colorata in rosa, situata dietro l'Hb $\mathrm{A}_{2}$ e cioè praticamente nella zona dove alla elettroforesi su carta si localizza dopo colorazione la frazione proteica denominata $\mathrm{A}_{3}$. Il reperto, lievissimo, è apparso costante se ricercato per tempo, e cioè prima che la frazione, continuando a spostarsi verso il catodo, esca dal campo elettroforetico. Allo spettrofotometro Beckmann, mentre la lettura a $540 \mathrm{~m} \mu$ ha dato valori bassissimi, assai vicini ai valori del blank e corrispondenti allo $0,15-0,17 \%$ di tutta l'Hb, la lettura a $280 \mathrm{~m} \mu$ ha dato valori da 50 a 200 , confermando così la presenza negli eluati di queste frazioni, di un forte contenuto proteico praticamente privo di $\mathrm{Hb}$.

Famiglia $I V$ - La mobilità elettroforetica della frazione lenta dei 5 membri della famiglia è identica a quella dell'Hb $\mathrm{S}$ e a quella dell'Hb lenta dei soggetti delle famiglie precedenti (fig. 22). Si ripete soltanto, come nella famiglia II, l'osservazione che nei soggetti ( $Z$. Geolinda e Gina) in cui la quota di Hb lenta è molto scarsa, la mobilità elettroforetica è lievemente maggiore di quella dell' $\mathrm{Hb} \mathrm{S}$ o di altre emoglobine lente presenti in concentrazione più elevata (figg. 22 e 23). Assai evidente su carta (fig. 22) come su amido (fig. 23) è la presenza nei soggetti Z. Geolinda e Gina di una quantità elevata di $\mathrm{Hb} \mathrm{A}_{2}$, e la presenza invece nelle rispettive figlie $\mathrm{M}$. Livia e G. Eufemia, di una quota normale. Nell'Hb di M. Livia si è ripetuta l'osservazione su piastra d'amido al termine dell'elettroforesi, di una tenuissima macchia nella zona della frazione $\mathrm{A}_{3}$.

Come le emoglobine delle precedenti famiglie, anche queste non si dividono dall' $\mathrm{Hb} \mathrm{A}_{1}$ a $\mathrm{pH}$ acido su carta o su piastra d'amido o gel d'amido (fig. 24), mentre si dividono invece nettamente su gel d'agar (fig. 25) con mobilità identica a quella delle emoglobine precedenti.

In cromatografia la mobilità dell' $\mathrm{Hb}$ lenta di questi soggetti è risultata identica a quella delle emoglobine lente delle precedenti famiglie (fig. 26). La suddivisione della frazione lenta in due bande è ben evidente in Z. Geolinda, assente negli altri membri.

Le curve di assorbimento all'U.V. dell'Hb $A_{1}$ e della frazione lenta hanno presentato costantemente un comportamento normale, e i quozienti $\frac{\mathrm{E}_{3 \cdot 000} \AA}{\mathrm{E}_{2 \cdot 800} \AA}$ e $\frac{\mathrm{E}_{2 \cdot 800}}{\mathrm{E}_{4 \cdot 150}} \frac{\AA}{\AA}$ sono risultati identici rispettivamente per ambedue le frazioni (Tabella I). Alla prova della denaturazione alcalina la frazione lenta è risultata completamente denaturata entro $6 \mathrm{o}^{\prime \prime}$. La quantità totale di $\mathrm{Hb} a-r$ è in tutti e 5 i soggetti al di sotto del $2,4 \%$ (Tabella I).

Famiglia $V$ - Su carta e su amido a pH alcalino (figg. 27-28) la mobilità elettroforetica della frazione lenta dei due soggetti A. Roberto e A. Franca è identica a quella dell'Hb S, dell'Hb D, [osservata precedentemente presso il Centro di Studi della Microcitemia di Roma (30)], e delle emoglobine precedenti. A pH acido sugli stessi supporti elettroforetici questa frazione non si divide dall' $\mathrm{Hb} \mathrm{A}_{1}$ (fig. 29). A differenza poi di tutte le altre emoglobine precedenti, essa non si divide dall'Hb $\mathrm{A}_{1}$ 
E. Silvestroni, I. Bianco, R. Lucci, E. Soffritri: Presenza di Emoglobina ( L », ecc.

neppure su gel d'agar (fig. $3^{\circ}$ ), comportandosi, in questa indagine, in modo assolutamente identico all'Hb D (fig. 3I).

Anche in cromatografia su Amberlite IRC-50 la frazione lenta di questi due soggetti ha la stessa mobilità dell'Hb $\mathrm{S}$ e dell' $\mathrm{Hb} \mathrm{D}$ (fig. 32). La quota di $\mathrm{Hb} \mathrm{A}_{2}$ è in ambedue i soggetti normale (Tabella $\mathrm{I}$ ), e la quantità di $\mathrm{Hb}$ a-r è intorno all' $\mathrm{I} \%$.

In conclusione, l'Hb lenta presente nelle prime 4 famiglie è caratterizzata da mobilità elettroforetica su carta e su amido a $\mathrm{pH}$ alcalino e su gel d'agar a $\mathrm{pH}$ acido, identica a quella dell' $\mathrm{Hb} \mathrm{S}$, e da mobilità cromatografica su Amberlite IRC-50 molto più lenta di quella dell'Hb $\mathrm{S}$. L'Hb lenta presente nell'ultima famiglia è caratterizzata da mobilità elettroforetica a $\mathrm{pH}$ alcalino identica a quella dell' $\mathrm{Hb} \mathrm{S}$ e delle emoglobine precedenti: a differenza di tutte queste, però, su gel d'agar a $\mathrm{pH}$ acido quest'ultima $\mathrm{Hb}$ non si divide dall' $\mathrm{Hb} \mathrm{A}_{1}$, e in cromatografia su Amberlite IRG-5o presenta mobilità identica a quella dell' $\mathrm{Hb} \mathrm{S}$ e non più lenta di questa, come è stato osservato per le emoglobine precedenti.

$\mathrm{Vi}$ sono dunque, fra l'Hb abnorme delle prime 4 famiglie e quella dell'ultima famiglia, precise e ben definite differenze di comportamento, che ne impongono logicamente una diversa classificazione.

\section{Discussione dei risultati e conclusioni}

Sono note oggi numerose varietà di emoglobine lente, la cui mobilità elettroforetica a $\mathrm{pH}$ alcalino è compresa fra quella dell'Hb $\mathrm{S}$ e quella dell' $\mathrm{Hb} \mathrm{F}$. Si conoscono infatti: l'Hb D e la cosiddetta $\mathrm{Hb}$ Lepore che hanno mobilità identica a quella dell'Hb S; l'Hb L e l'Hb P che hanno mobilità identica fra loro e lievemente maggiore di quella cell' $\mathrm{Hb} \mathrm{S}$; l'Hb $\mathrm{G}$ che ha mobilità ancora maggiore di quella dell'Hb L, ma minore di quella dell'Hb F; e l'Hb Q che è compresa fra l'Hb G e l'Hb F. Di tutte queste emoglobine sono noti però oggi, oltre alla mobilità elettroforetica che non sempre è sufficiente a discriminarle, anche altri caratteri che meglio ne definiscono l'individualità.

L'Hb D, illustrata per la prima volta da Itano nel I95 (4) e poi da numerosi altri Autori in osservazioni isolate e in casistiche (I5-16-1 7-I 8-19-20-21-22-23-24-2526-27-28-29-30), è caratterizzata da mobilità elettroforetica a $\mathrm{pH}$ alcalino eguale a quella dell'Hb S, da mobilità cromatografica in Amberlite IRC-5o anch'essa eguale a quella dell'Hb S (3I), ma da solubilità normale e assenza del fenomeno falciforme (14).

L'Hb Lepore, descritta da Gerald e Diamond (32) in una famiglia italiana e successivamente da Pearson e Coll (33) in un'altra famiglia di origine siciliana, è presente sempre in percentuali del 9-I I\%, è visibile solo su blocco d'amido a $\mathrm{pH}$ alcalino, ove dimostra mobilità identica a quella dell' $\mathrm{Hb} \mathrm{S}$, mentre in elettroforesi libera a $\mathrm{pH}$ acido, su gel di agar e in cromatografia su Amberlite IRG-5o non si divide dall' $\mathrm{Hb} \mathrm{A}_{1}$.

L'Hb L è stata descritta da Ager e Lehmann (34) come un'Hb lenta che all'elettroforesi a $\mathrm{pH}$ alcalino ha mobilità lievemente maggiore di quella dell' $\mathrm{Hb} \mathrm{S}$, mentre 
in cromatografia ha mobilità notevolmente minore e si localizza fra l'Hb S e l'Hb C. Tali caratteristiche sono state confermate successivamente in altre osservazioni (3536-37).

L'Hb P, illustrata da Schneider e Haggard (38-39) inizialmente col nome di $\mathrm{Hb}$ Galveston, e confermata in seguito da altri Autori (40-4r), presenta all'elettroforesi a $\mathrm{pH}$ alcalino mobilità eguale a quella dell' $\mathrm{Hb} \mathrm{L}$, ma all'elettroforesi in fase libera a $\mathrm{pH}$ acido e in gel d'agar a $\mathrm{pH}$ acido, a differenza dell' $\mathrm{Hb} \mathrm{L}$ non si divide dall' $\mathrm{Hb}$ $\mathrm{A}_{1}$. Anche in cromatografia su Amberlite IRC-5o questa $\mathrm{Hb}$ non si divide dall' $\mathrm{Hb} \mathrm{A}_{1}$, senza neppur essere però assolutamente identica ad essa per mobilità, dato che le miscele di $\mathrm{Hb} \mathrm{A}+\mathrm{Hb} \mathrm{P}$ danno luogo ad una banda più diffusa di quella dell' $\mathrm{Hb}$ $\mathrm{A}_{1}$ e che si estende dall' $\mathrm{Hb} \mathrm{A}$ all' $\mathrm{Hb} \mathrm{S}$. Da quest'ultima a sua volta l'Hb $\mathrm{P}$ si separa in cromatografia ed è appunto con l'applicazione della cromatografia su frazioni eluite dopo elettroforesi, che è stato possibile svelare la presenza di $\mathrm{Hb} \mathrm{P}$ in soggetti portatori contemporaneamente di $\mathrm{Hb} \mathrm{S}$ e di $\mathrm{Hb} \mathrm{P}\left(4^{-0}-4 \mathrm{I}\right)$.

L'Hb G, descritta da Edington e Lehmann (42) come un'Hb che all'elettroforesi a $\mathrm{pH}$ alcalino ha mobilità nettamente maggiore di quella della $\mathrm{Hb} \mathrm{S}$ e dell' $\mathrm{Hb} \mathrm{L}$, ha dimostrato in osservazioni successive (43-44-45-46-47-48) altre proprietà ben definite, e cioè: divisione dall' $\mathrm{Hb} \mathrm{A}$ anche all'elettroforesi in fase libera a $\mathrm{pH}$ acido $\mathrm{e}$ in cromatografia su colonna di Amberlite IRC-50, ove si localizza fra l'Hb P e l'Hb S; incapacità viceversa a dividersi dall' $\mathrm{Hb} \mathrm{A}$ su gel d'agar a $\mathrm{pH}$ acido.

L'Hb Q, finora nota solo dall'osservazione di Vella e Coll. (49), si muove su carta a $\mathrm{pH}$ alcalino un pò più lentamente dell'Hb $\mathrm{F}$ e un pò più rapidamente dell'Hb G. La sua differenziazione dall'Hb $\mathrm{G}$ è resa certa però dal comportamento in cromatografia e su gel d'agar, risultando in cromatografia la mobilità dell' $\mathrm{Hb} Q$ compresa fra quella dell' $\mathrm{Hb} \mathrm{S}$ e quella dell' $\mathrm{Hb} \mathrm{L}$, mentre l'Hb G sta fra l'Hb A e l'Hb S; e risultando inoltre su gel d'agar la mobilità dell' $\mathrm{Hb} Q$ assai simile a quella dell' $\mathrm{Hb} \mathrm{L}$, a differenza dell'Hb $\mathrm{G}$ che non si divide dall'Hb A.

Ancora poco note e non sufficientemente differenziate risultano altre emoglobine lente, di recente segnalate nella letteratura: l'Hb Stanleyville I (50-5I), che su carta a $\mathrm{pH}$ alcalino ha la stessa mobilità della $\mathrm{Hb} \mathrm{L}$ o $\mathrm{P}$, mentre in cromatografia si comporta come l'Hb S o D; l'Hb Stanleyville II (5I), che su carta si comporta come l'Hb S o D, mentre in cromatografia si localizza fra l'Hb L e l'Hb S; l'Hb Cipro I (52), che ha forti somiglianze con l'Hb P per il suo comportamento in elettroforesi $\mathrm{e}$ in cromatografia, ma che presenta poi una resistenza alla denaturazione alcalina maggiore di quella di tutte le altre emoglobine adulte.

Dall'esame dei dati raccolti sull'Hb osservata nelle prime 4 famiglie della presente casistica, si ricava che dal lato elettroforetico e cromatografico il comportamento di questa $\mathrm{Hb}$ corrisponde fondamentalmente a quello dell' $\mathrm{Hb} \mathrm{L}$ : esso è caratterizzato da mobilità elettroforetica eguale a quella dell' $\mathrm{Hb} \mathrm{S}$ e da mobilità cromatografica notevolmente inferiore a quella dell'Hb S. Si può escludere per la sua mobilità elettroforetica che si tratti di $\mathrm{Hb} Q$ (che all'elettroforesi alcalina è molto più rapida dell' $\mathrm{Hb} \mathrm{S}$ ) o di $\mathrm{Hb} \mathrm{C}$ (che è notoriamente molto più lenta dell' $\mathrm{Hb} \mathrm{S}$ ); e si può escludere per il suo comportamento cromatografico ed elettroforetico che si 
tratti di $\mathrm{Hb} \mathrm{P}$ o di $\mathrm{Hb}$ Lepore, le quali hanno mobilità elettroforetica a $\mathrm{pH}$ alcalino eguale a quella dell'Hb L, ma in cromatografia e su gel d'agar a $\mathrm{pH}$ acido non si separano affatto dall' $\mathrm{Hb} \mathrm{A}$.

Oltre al comportamento cromatografico l' $\mathrm{Hb}$ in esame ha in comune con l'Hb $\mathrm{L}$, e diversamente dalle altre emoglobine lente $(\mathrm{Hb} \mathrm{D}, \mathrm{Hb} \mathrm{P}, \mathrm{Hb} \mathrm{G}$ ) la netta separabilità dall' $\mathrm{Hb} \mathrm{A}$ in gel d'agar a $\mathrm{pH}$ acido. Ciò che non sembra corrispondere esattamente, per la presente $\mathrm{Hb}$, al comportamento della $\mathrm{Hb} \mathrm{L}$, quale è ormai sancito nella letteratura, è la sua mobilità elettroforetica a $\mathrm{pH}$ alcalino: l'Hb lenta di queste 4 famiglie presenta infatti invariabilmente mobilità identica a quella dell'Hb S (e per questo carattere la famiglia I, per esempio, è stata classificata precedentemente, in una pubblicazione preliminare ( $\mathrm{I}$ ), come $\mathrm{Hb} \mathrm{D}$ ) e non maggiore di quella della $\mathrm{Hb} \mathrm{S}$, come è descritto per l'Hb L. Come si è già detto, però, è stato possibile documentare che la velocità di migrazione della frazione lenta è, entro limiti abbastanza ampi, in funzione della sua concentrazione (figg. IO, II, 22, 23): questa frazione ha infatti mobilità eguale o maggiore a quella dell'Hb $\mathrm{S}$ a seconda della sua concentrazione I reperti sono costanti e assolutamente dimostrativi, e concordano con analoga osservazione fatta da Vella e Coll. (49) a proposito dell'Hb Q. Il fenomeno, definito da questi Autori come una sorta di «interazione fra emoglobine a mobilità elettroforetica affine », è evidentemente soltanto espressione di un comportamento generale in elettroforesi, per cui, entro certi limiti, quanto più piccola è la quantità di $\mathrm{Hb}$ sottoposta ad elettroforesi, tanto maggiore è la sua mobilità.

Esclusa dunque in base a questi accertamenti, l'opportunità di attribuire valore differenziale al comportamento elettroforetico di questa $\mathrm{Hb}$ lenta, l'unica classificazione che di essa può esser fatta in base alle attuali conoscenze, è quella di $\mathrm{Hb} \mathrm{L}$.

Le presenti osservazioni mettono pertanto in luce che l'elettroforesi alcalina, quale mezzo di identificazione e classificazione di emoglobine abnormi, ha dei limiti ben precisi che non possono essere eccessivamente allargati senza pericolo di errori; e che lo studio di un'Hb abnorme deve oggi necessariamente comprendere altri metodi di indagine, oltre all'elettroforesi alcalina.

Nei portatori di $\mathrm{Hb} \mathrm{L}$ di queste 4 famiglie è stato osservato con una certa frequenza, ma non costantemente, il reperto in cromatografia, nella zona della frazione $\mathrm{L}$, di due bande allineate $\mathrm{e}$ ben distinte, anzichè di una sola. Il fenomeno non è ancora chiarito: esso potrebbe essere soltanto un artefatto dovuto all'invecchiamento dell'Hb o alla lunga durata della cromatografia, ma potrebbe anche essere manifestazione propria, per quanto incostante, dell'Hb L.

Interessante è anche la grande variabilità della quota di $\mathrm{Hb} \mathrm{L}$ presente nei singoli soggetti di queste 4 famiglie, e che è risultata oscillante dal 9 al $47 \%$, senza uniformità di comportamento nell'ambito della stessa famiglia: è stato piuttosto frequente infatti il reperto di notevoli differenze nella quantità di $\mathrm{Hb} \mathrm{L}$, per esempio fra genitori e figli.

Di scarso rilievo appare il reperto, segnalato su piastra d'amido in due di queste famiglie, di una terza frazione lenta, oltre l'Hb L e l'Hb $\mathrm{A}_{2}$, localizzata dietro l' $\mathrm{Hb}$ $A_{2}$, e ciò̀ nella zona dove su carta si localizza la frazione proteica $A_{3}$ : a confermare 
che si tratta proprio dell' $A_{3}$ divenuta visibile perchè debolmente colorata in rosa dall' $\mathrm{Hb}$, sta il fatto che allo spettrofotometro Beckmann mentre la lettura a $54^{\circ}$ $\mathrm{m} \mu$ ha dato sempre valori molto bassi, corrispondenti allo $0, \mathrm{I} 5-\mathrm{o}, \mathrm{I} 7 \%$ dell' $\mathrm{Hb}$ totale, a $280 \mathrm{~m} \mu$ e cioè nella zona di assorbimento delle proteine, la lettura ha dato valori molto più alti, e cioè fra 150 e 200 . E probabile che il dato, verosimilmente identificabile col reperto segnalato da altri Autori (53) nell'Hb di microcitemici e denominato $\mathrm{B}_{2}$, sia più frequente di quanto finora segnalato, e che possa talora esser sfuggito al rilievo per la sua scarsa entità o per la tardiva esplorazione della piastra d'amido durante la corsa elettroforetica.

La curva di assorbimento nell'U.V. e il comportamento di fronte agli alcali della frazione emoglobinica lenta, eluita dalla piastra d'amido, sono risultati del tutto simili a quelli dell'Hb $\mathrm{A}$; e anche $\mathrm{i}$ quozienti $\frac{\mathrm{E}_{2 \cdot 800} \AA}{\mathrm{E}_{\mathbf{4} \cdot \mathbf{1 5 0}} \AA} \mathrm{e} \frac{\mathrm{E}_{\mathbf{3} \cdot 000} \AA}{\mathrm{E}_{\mathbf{2} \cdot 800} \AA}$ sono risultati rispettivamente assai simili per l'Hb A e per l'Hb L, e cioc̀ compresi fra 0,25 e 0,29 il primo, fra 0,46 e $0,5^{2}$ il secondo per ambedue le frazioni (Tabella I), senza quelle differenze di comportamento osservate per altre frazioni emoglobiniche, per esempio l'Hb $\mathrm{H}(5-54)$. La quantità totale di $\mathrm{Hb} a-r$ è risultata normale in tutti $\mathrm{i}$ portatori di $\mathrm{Hb}$ L, salvo che nella bimba B. Antonella, affetta da grave anemia del tutto simile al morbo di Cooley; e la solubilità dell'Hb totale non è apparsa modificata dalla presenza di quote anche elevate di $\mathrm{Hb} \mathrm{L}$.

Nei riguardi dell' $\mathrm{Hb} \mathrm{A}_{2}$ si è osservata viceversa nelle famiglie in cui era presente anche la microcitemia (II e IV) un'assoluta incostanza di quell'aumento della frazione stessa, che è caratteristico della microcitemia: sembra in complesso (Tabella I) che detto aumento sia presente solo quando la quota di $\mathrm{Hb} \mathrm{L}$ è bassa, e cioè intorno al Io- $5 \%$. Il rapporto fra i due fatti non è facilmente spiegabile, e il problema rientra nella più vasta e complessa questione dei rapporti fra microcitemia ed emoglobine lente, che sarà trattata in altro lavoro.

Nella famiglia $V$, l'Hb lenta differisce da quella delle altre 4 famiglie per il comportamento in cromatografia e su gel d'agar, il quale corrisponde esattamente al comportamento dell' $\mathrm{Hb} \mathrm{D}$, anzichè a quello dell'Hb $\mathrm{L}$. Come l'Hb $\mathrm{D}$, infatti, l'Hb lenta presente in questa famiglia ha mobilità elettroforetica a $\mathrm{pH}$ alcalino identica a quella dell'Hb S, ma su gel d'agar non si divide dall'Hb A e in cromatografia presenta di nuovo mobilità identica a quella dell'Hb S. Questi due caratteri sono sufficienti a distinguere la presente $\mathrm{Hb}$, sia dall'Hb L, che su gel d'agar si divide dall' $\mathrm{Hb}$ $\mathrm{A}$ e in cromatografia è molto più lenta dell' $\mathrm{Hb} \mathrm{S}$, sia dall' $\mathrm{Hb} \mathrm{P}$ che all'elettroforesi alcalina si muove come l'Hb $\mathrm{S}$, ma che non si separa poi dall'Hb A nè su gel d'agar nè in cromatografia.

La casistica illustrata nel presente lavoro comprende dunque casi di $\mathrm{Hb} \mathrm{L}$ e casi di $\mathrm{Hb} \mathrm{D}$. I primi risultano in complesso piuttosto frequenti nella zona del Ferrarese, essendone stati individuati fino ad oggi già 4 ceppi familiari diversi, i quali costituiscono inoltre, a quanto ci risulta le prime osservazioni di $\mathrm{Hb} \mathrm{L}$ segnalate finora in Italia. I casi di $\mathrm{Hb} \mathrm{D}$ appaiono in confronto molto più rari: risulta però già accertata per questa $\mathrm{Hb}$ la sua presenza in regioni d'Italia assai distanti tra loro, essendo la 
presente famiglia di origine bolognese (3), mentre il primo ceppo illustrato in Italia (30) e nel quale $\mathrm{i}$ recenti metodi di indagine hanno accertato la presenza dei caratteri dell'Hb $\mathrm{D}$, era di origine calabrese.

Con le presenti osservazioni si aggiunge dunque ai reperti già noti in Italia di $\mathrm{Hb} \mathrm{S}$ (55), di $\mathrm{Hb} \mathrm{G}(46)$, di $\mathrm{Hb} \mathrm{D}$ (30), di $\mathrm{Hb} \mathrm{H}$ (5-53-56-57), di $\mathrm{Hb} \mathrm{A}_{2}$ abbondante (58), di $\mathrm{Hb} \mathrm{K}$ e di $\mathrm{Hb} \mathrm{J}$ (59), la segnalazione di un'altra $\mathrm{Hb}$ abnorme, l'Hb $\mathrm{L}$, e nuove acquisizioni si aggiungono circa la diffusione in Italia dell'Hb D. Il problema delle emoglobine abnormi si arricchisce così di nuovi dati, che ne rendono sempre più interessante l'ulteriore indagine su tutto il territorio nazionale.

La presente casistica documenta infine per ambedue le emoglobine abnormi illustrate il comportamento ereditario costantemente corrispondente a quello di un carattere mendeliano dominante semplice. In tutti e $5 \mathrm{i}$ ceppi familiari si assiste infatti (fig. I) alla trasmissione ereditaria del carattere dai genitori ai figli. La casistica è ancora troppo scarsa per controllare se negli incroci fra un normale e un portatore eterozigote di $\mathrm{Hb}$ abnorme i figli siano realmente per il $50 \%$ normali e per il $50 \%$ portatori di $\mathrm{Hb}$ abnorme, come prevede la legge mendeliana della dominanza. Così pure merita di essere ulteriormente indagata dal punto di vista genetico, attraverso lo studio di più ampia casistica, la notevole variabilità da soggetto a soggetto della quota di $\mathrm{Hb}$ lenta.

A questi si aggiungono ancora altri e complessi problemi genetici, riguardanti i rapporti fra $\mathrm{Hb}$ lenta e microcitemia, per i quali la presente casistica offre elementi di studio, che saranno illustrati e discussi in un prossimo lavoro.

\section{Riassunto}

Gli AA. illustrano dal lato elettroforetico, biochimico, spettrofotometrico e cro matografico l'Hb lenta osservata in 5 ceppi familiari di origine ferrarese e bolognese, e dimostrano che-in 4 di detti ceppi si tratta di $\mathrm{Hb} \mathrm{L}$, mentre nella $\mathrm{V}$ famiglia si tratta di $\mathrm{Hb} \mathrm{D}$. Alle numerose emoglobine abnormi già segnalate in Italia ( $\mathrm{Hb} \mathrm{S}$, $\mathrm{Hb} \mathrm{G}, \mathrm{Hb} \mathrm{D}, \mathrm{Hb} \mathrm{K}, \mathrm{Hb} \mathrm{H}, \mathrm{Hb}$ J, $\mathrm{Hb} \mathrm{A}_{2}$ abbondante) si aggiunge così un'altra $\mathrm{Hb}$, $l^{\prime} \mathrm{Hb} \mathrm{L}$, che risulta affatto rara nella zona del Ferrarese. Nei riguardi dell' $\mathrm{Hb} \mathrm{D}$, viene sottolineata invece la sua presenza in regioni assai diverse d'Italia, essendo la prima famiglia, precedentemente illustrata, di origine calabrese, e la presente invece di origine bolognese.

\section{Bibliografia}

1. Lucar R. e Soffritti E.: Prima osservazione di $\mathrm{Hb}$ «D » e microcitemia in 4 membri di una famiglia ferrarese. Min. Med., 50: $2832,1959$.

2. Lucai R. e Soffritti E.: Presenza di emoglobine abnormi nella popolazione del Delta Padano. Arcisped. S. Anna di Ferrara, I2: 419, I959.

3. Lucai R., Soffritti E. e Borgatti L.: Descrizione di tre nuovi nuclei familiari di portatori di Hb abnorme nel Delta Padano. In corso di stampa. 
4. Silvestroni E. e Bianco I.: Su alcuni nuovi reperti elettroforetici dell'emoglobine unama normale e microcitemica. Progr. Med., 13: 225, 1957.

5. Silvestroni E., Bianco I., Muzzolini M., Modiano G. e Vallisneri E.: Studio biochimico, elettroforetico e spettrofotometrico dell'emoglobina di malati di anemia microcitica costituzionale e di morbo di Cooley. Progr. Med., I3: 705, 1957.

6. Smithies O.: Zone electrophoresis in starch gels. Group variations in the serum proteins of normal human adults. Biochem. J., 6r: 629, I955.

7. Fessas Ph. e Mastrokalos N.: Demonstration of small components in red cell haemolysates by starch-gel electrophoresis. Nature, I83: 126I, 1959.

8. Robinson A. R., Robson M., Harrison A. P. e Zuelzer W. W.: A new technique for differentiation of hemoglobin. Journ. Lab. Clin. Med., 50: 745, 1957.

9. Huisman T. H. J. e Prins H. K.: Chromatographic estimation of four different human hemoglobins: J. Lab. Glin. Med., 46: 255, 1955 .

io. Singer G., Ghernoff A. J. e Singer L.: Studies on abnormal hemoglobins. I. Their demonstration in sickle cell anemia and other hematologic disorders by means of alkali denaturation. Blood, 6: 413; 1951.

I I. Itano H. A.: Solubilities of naturally occurring mixtures of human hemoglobin. Arch. Biochem. Biophys., 47: 148 , I953.

12. Liquori A. M. e Bertinotri F.: Ricerche chimico-fisiche sull'emoglobina del morbo di Cooley. Ric. Scient., 2 I : I 2OO, I95I.

13. Mearder V.J. e Conley C. L.: Electrophoresis of hemoglobin on agar gels. Frequency of hemoglobin D in a negro population. Bull. Johns Hopkins Hosp., I05: 77, 1959.

14. Itano H. A.: A third abnormal hemoglobin associated with hereditary hemolytic anemia. Proc. Nat. Acad. Sci., 37: 775, I951.

15. Sturgeon P., Itano H. A. e Bergren W. R.: Clinical manifestations of inherited abnormal hemoglobins. I. The interaction of hemoglobin $S$ with hemoglobin D. Blood, ro: 389,1955 .

16. White J. C. e Beaven G. H.: A review of the varieties of human haemoglobin in health and disease. J. Clin. Path., 7: I 75, I954.

17. Cabannes R., Sendra L. e Dalaut J. P.: Hémoglobinose D: anomalie hémoglobinique héréditaire retrouvée chez l'Algérien musulman: observation de deux familles. Algérie Méd., 59: 387, 1955.

i8. Bird G. W. G., Lehmann H. e Mourant A. E.: A third example of haemoglobin D. Trans. Roy. Soc. Trop. Med. Hyg., 49: 399, I955.

19. Bird G. W. G. e Lehmann H.: The finding of haemoglobin D disease in a Sikh. Man, 56: I, 1956.

20. Stewart J. W. e Maciver J. E.: Sickle cell-haemoglobin D disease in a mulatto girl. Lancet, i : 23 , 1956.

21. Hynes M. e Lehmann H.: Haemoglobin D in a persian girl: the first case of haemoglobin D-thalassaemia. Brit. Med. J., 2: 923 , 1956 .

22. Chernoff A. I.: The hemoglobin D syndromes. Blood, r3: 116, $195^{8}$.

23. Bird G. W. G. e Lehmann H.: Haemoglobin D in India. Brit. Med. J., I : 514, 1956.

24. Bird G. W. G., Inin E. W., Lehmann H. e Mourant A. E.: Heredity, 10 : 425, 1956.

25. Jacob G. F., Lehmann H. e Raper A. B.: East Afr. Med. Journ., 33: 135, i 956.

26. Aksoy M. e Lehmann H.: A further example of haemoglobin D in a Turkish family. Trans. Roy. Soc. Trop. Med. Hyg., 50: 178 , 1956.

27. Cabannes R., Duzer A., Portier A., Massonnat J., Sendra L. e Buhr J. L.: Hémoglobines anormales chez l'Algérien musulman; bilan statistique de deux années d'études portant sur 1.877 hémoglobinogrammes. Le Sang, 27: 580, 1956.

28. Cabannes R.: Algérie Médicale, 6I : 75 I, 1957.

29. Chernoff A. I.: On the prevalence of hemoglobin D in the American negro. Blood, i I: 907, I956.

3o. Silvestroni E., Bianco I., Muzzolint M.: Emoglobina D in una famiglia italiana di origine calabrese. Policlinico, Sez. Prat., 66: 4I, r959.

31. Huisman T. H. J.: The identification of human haemoglobins. Abnormal Haemoglobins. Blackwell Scient. Publ., Oxford, I8, r959.

32. Gerald P. S. e Diamond L. K.: A new hereditary hemoglobinopathy (the Lepore trait) and its interaction with thalassemia trait. Blood, 13: 835 , I958. 
33. Pearson H. A., Gerald P. S. e Diamond L. K.: Thalassemia intermedia due to interaction of Lepore trait with thalassemia trait. Journ. Dis. Child, 97: 464, 1959 .

34. Ager J. A. M. e Lehmann H.: Haemoglobin L.: a new haemoglobin found in a punjabi hindu. Brit. Med. Journ., 2: 142, 1957.

35. Sukumaran P. K., Sanghvi L. D., Ager J. A. M. e Lehmann H.: Acta Gen. Stat. Med., 9: 202 , 1959.

36. Vella F. e Singh R. B.: Haemoglobin I in Indians in Malaya. Trans. Roy. Soc. Trop. Med. Hyg., 53: $535,1959$.

37. Vella F.: Abnormal haemoglobins in Indians in Singapore with two instances of haemoglobin L. Journ. Ind. Med. Ass., 33: 207, 1959.

38. Schneider R. G. e Haggard M. E.: A new hemoglobin variant exhibiting anomalous electrophoretic behaviour. Nature, I80: 1486, 1957.

39. Schneider R. G. e Haggard M. E.: Haemoglobin P (the "Galveston" type). Nature, 182: $322,1958$.

40. Dherte P., Lehmann H. e Vandepitte J.: Haemoglobin P in a family in the belgian Congo. Nature, 184 : I 133, 1959 .

41. Lambotte-Legrand J. e C., Ager J. A. M. e Lehmann H.: L'hémoglobinose P: à propos d'un cas d'association des hémoglobines $\mathrm{P}$ et $\mathrm{S}$. Rev. Hémat., ${ }_{5}$ : 10 , 1960 .

42. Edington G. M. e Lehmann H.: Haemoglobin G: a new haemoglobin found in a west african. Lancet. 2: 173,1954 .

43. Edington G. M., Lehmann H. e Sahneider R. G.: Nature, 175: 850, 1955.

44. Schneider G. R. e Genereaux B. D.: A second instance of haemoglobin G in an american negro family. Trans. Roy. Soc. Trop. Med. Hyg., 50: 614, $195^{6}$.

45. Schwartz H. C., Spaet T. H., Zuelzer W. W., Neel J. V., Robinson A. R. e Kaufman S. F.: Conbination of hemoglobin $\mathrm{G}$, hemoglobin $\mathrm{S}$ and thalassemia occurring in one family. Blood, 12: 238, 1957,

46. Silvestroni E. e Bianco I.: Associazione di Hb G e microcitemia in due membri di una famiglia italiana del Ferrarese. Policlinico, Sez. Prat., 65: 203, $195^{8}$.

47. Veilla F., Ager J. A. M. e Lehmann H.: An abnormal haemoglobin in a chinese: haemoglobin G. Nature, I82: 460 , I $95^{8}$.

48. Schneider R. G. e Haggard M. E.: A family with hemoglobin G. Journ. Lab. Clin. Med., 55: 6o, ig6o.

49. Vella F., Wells R. H. G., Ager J. A. M. e Lehmann H.: A haemoglobinopathy involving haemoglobin $H$ and a new (Q) haemoglobin. Brit. Med. Journ., I: 752, $195^{8}$.

5o. Dherte P., Vandepitte J., Ager J. A. M. e Lemmann H.: Stanleyville I and II : two new variants of adult haemoglobin. Brit. Med. Journ., 2: 282, 1959.

5i. Schneider R. G. e Haggard M. E.: A new haemoglobin variant in an american negro. Brit. Med. Journ., 2: 285 , I959.

52. Gillespie J. E. O’N, White J. C., Ellis M. J., Beaven G. H., Gratzer W. B., Shooter E. M., ParkHouse R. M. E.: A haemoglobin with unusual alkaline-denaturation properties in a Turkish-Cypriot woman. Nature, 184: 1876, 1959 .

53. Ceppellini R.: L'emoglobina normale lenta $A_{2}$. Symposium Geneticae Haematologicae VII Congr. Inter. Emat., Acta Gen. Med. Gemell., supplem., II, 47, I959.

54. Silvestroni E., Bianco I. e Muzzolini M.: Presenza di una seconda frazione emoglobinica rapida nei portatori di Hb H. Policlinico, Sez. Prat., 67: 41, I960.

55. Silvestroni E.: Emopatie familiari. Relaz. 50 Congr. Soc. It. Med. Int., Pozzi Ed., Roma I949.

56. Silvestroni E. e Bianco I.: Un caso di anemia microcitica costituzionale-emoglobina H. Policlinico, Sez. Prat., 64: I30I, 1957.

57. Bianco I. e Muzzolini M.: Studio clinico-ematologico e genetico di 4 nuovi casi di malattia da $\mathrm{Hb} \mathrm{H}-\mathrm{mi}-$ crocitemia. Progr. Med., I5: 536, 1959 .

58. Silvestroni E. e Bianco I.: Sull'esistenza nella popolazione italiana di soggetti non microcitemici portatori di un'elevata quota di emoglobina adulta lenta $\left(\mathrm{Hb} \mathrm{A}_{2}\right)$ e sui loro rapporti con i malati di anemia microcitica. Policlinico, Sez. Prat., 64: I868, r957.

59. Silvestroni E., Bianco I., Muzzolini M. e Roberti L.: Presenza di emoglobina K e di emoglobina J nella popolazione dell'Italia meridionale. Progr. Med., 14: 618, $195^{8 .}$ 


\section{RÉSUMÉ}

Les Auteurs décrivent, du point de vue électrophorétique, biochimique, spectrophotométrique et chromatographique l'Hb lente, observée chez 5 groupes familiaux de Ferrare et Boulogne, et démontrent que chez 4 de ces familles il s'agit d'Hb L, tandis que chez la cinquième famille il s'agit d'Hb D. Aux nombreuses hémoglobines abnormes déjà signalées en Italie (HB $S$, $\mathrm{Hb} \mathrm{G}, \mathrm{Hb} \mathrm{D}, \mathrm{Hb} \mathrm{K}, \mathrm{Hb} \mathrm{H}, \mathrm{Hb} \mathrm{J}, \mathrm{Hb} \mathrm{A}_{2}$ abondante) s'ajoute ainsi l'Hb $\mathrm{L}$, assez fréquente dans la région de Ferrare.

En ce qui concerne l'Hb D, l'on remarque sa présence dans des régions diverses, étant donné que la première famille, déjà décrite, était originaire de la Calabre, tandis que cette dernière est originaire de Bologne.

\section{SUMMARY}

The Authors describe from the electro. phoretic, biochemical, spectrophotometric and chromatographic points of view the slow $\mathrm{HIb}$ as observed in 5 family groups from Ferrara and Bologna, in 4 of which they found an $\mathrm{Hb} \mathrm{L}$, while the 5 th presented an Hb D. A new $\mathrm{Hb}$ is therefore added to the numerous abonrmal hemoglobines already found in Italy ( $\mathrm{Hb} \mathrm{S}, \mathrm{Hb} \mathrm{G}, \mathrm{Hb} \mathrm{D}, \mathrm{Hb} \mathrm{K}, \mathrm{Hb} \mathrm{H}, \mathrm{Hb}$ J, abundant $\mathrm{Hb} \mathrm{A}_{2}$ ): the $\mathrm{Hb} \mathrm{L}$, which is rather frequent in the region of Ferrara.

As for the $\mathrm{Hb} \mathrm{D}$, its presence in different regions of Italy is stressed, in as far as the first family, previously described, came from Calabria, and the present one from Bologna.

\section{ZUSAMMENFASSUNG}

Die Verfasser beschreiben elektrophoretisch, biochemisch, spektrophotometrisch und chromatographisch das langsame, in fünf Familien aus Ferrara und Bologna beobachtete Hämoglobin und beweisen dass es, in 4 diesen Familien, um $\mathrm{Hb} \mathrm{L}$ sich handelt, während in der fünfte handelt es sich um $\mathrm{Hb} \mathrm{D}$. Ein neues $\mathrm{Hb}$ wird so an den vielen, in Italien schon gefunden abnormen Hämoglobinen ( $\mathrm{Hb} \mathrm{S}, \mathrm{Hb} \mathrm{G}, \mathrm{Hb}$ $\mathrm{D}, \mathrm{Hb} \mathrm{K}, \mathrm{Hb} \mathrm{H}, \mathrm{Hb} J$, reichliches $\mathrm{Hb} \mathrm{A}_{2}$ ) hinzugesetzt: das $\mathrm{Hb} \mathrm{L}$ die, in der Zone Ferrara, häufig gefunden wird.

Die Verfasser bemerken auch die Anwesenheit des $\mathrm{Hb} \mathrm{D}$ in verschiedenen Gegenden, wie die erste, schon beschriebene Familie aus Kalabrien kam, und diese lätzte aus Bologna. 